FedUni ResearchOnline

http://researchonline.federation.edu.au

This is the author's accepted version of the following publication:

Armaghani, D., Momeni, E., Abad, S., Khandelwal, M. (2015)

Feasibility of ANFIS model for prediction of ground vibrations

resulting from quarry blasting. Environmental Earth Sciences,

74(4), 2845-2860.

The version displayed here may differ from the final published version.

The final publication is available at:

http://doi.org/10.1007/s12665-015-4305-y

Copyright $\odot 2015$, Springer-Verlag Berlin Heidelberg 
Feasibility of ANFIS Model for Prediction of Ground Vibrations Resulting from

\title{
Quarry Blasting
}

Danial Jahed Armaghani ${ }^{\mathrm{a}}$, Ehsan Momeni ${ }^{\mathrm{b}}$, Seyed Vahid Alavi Nezhad Khalil Abad, Manoj Khandelwal ${ }^{\mathrm{d} *}$

${ }^{a}$ Department of Geotechnics and Transportation, Faculty of Civil Engineering, Universiti Teknologi Malaysia, 81310, UTM, Skudai, Johor, Malaysia. Email: danialarmaghani@yahoo.com.

${ }^{\mathrm{b}}$ Department of Geotechnics and Transportation, Faculty of Civil Engineering, Universiti Teknologi Malaysia, 81310, UTM, Skudai, Johor, Malaysia. Email: mehsan23@live.utm.my.

c Department of Geotechnics and Transportation, Faculty of Civil Engineering, Universiti Teknologi Malaysia (UTM), Skudai 81310, Johor, Malaysia. Email: vankaseyed2@live.utm.my.

$\mathrm{d}^{\mathrm{d}}$ Faculty of Science and Technology, Federation University Australia, PO Box 663, Ballarat, Victoria 3353, Australia Phone: +61 $353279821 \quad$ Email:

m.khandelwal@federation.edu.au (Corresponding Author).

\begin{abstract}
One of the most significant environmental issues of blasting operations is ground vibration which can cause damage to the surrounding residents and structures. Hence, it is a major concern to predict and subsequently control the ground vibration due to blasting. This paper presents two artificial intelligence (AI) techniques namely adaptive neuro-fuzzy inference system (ANFIS) and artificial neural network (ANN) for the prediction of ground vibration in quarry blasting site. For this purpose, blasting parameters as well as ground vibrations of 109 blasting operations were measured in ISB granite quarry, Johor, Malaysia. Moreover, an empirical equation was also proposed based on the measured data. Several AI-based models were trained and tested using the measured data to determine the optimum models. Each model involved two inputs (maximum
\end{abstract}


Blasting is a common technique for rock fragmentation in quarries, mining operations and some civil engineering applications such as tunneling and leveling/road construction. In quarry works, several rows of blast-holes (almost parallel to the free face of the bench) are drilled and blasted. These operations cause several impacts such as ground vibration, air-overpressure, flyrock, and back-break in the blasting environmental zone (Khandelwal and Singh 2009; Jahed Armaghani et al. 2013; Hajihassani et al. 2014a; Raina et al. 2014; Ebrahimi et al. 2015). Among them, ground vibration is recognized as an undesirable phenomenon which may lead damage to the surrounding structures (Singh and Singh 2005; Ozer et al. 2008)

When an explosive is detonated in a blast-hole, chemical reaction of the explosives produces a high pressure and temperature gas. This gas pressure crushes the rock adjacent to the blast-hole. The detonation pressure decays or dissipates quickly. A wave motion is created in the ground by the strain waves conveyed to the surrounding rocks (Duvall and Petkof 1959). Due to various breakage mechanism, like radial cracking, crushing, and reflection breakage in the free face, the strain energy carried out by these strain waves fragments the rock mass (Khandelwal et al. 2011). The strain waves are propagated as the elastic wave when the stress wave intensity reduces to the 
ground level. These waves are known as ground vibration. The ground vibration can be spread from the blast-hole in all direction (Dowding 1985).

High ground vibration can cause damage to the surrounding structures, groundwater conduits, and ecology of the nearby area (Khandelwal and Singh 2006; Monjezi et al. 2010). The ground vibrations are measured in terms of peak particle velocity (PPV) and frequency. As reported in several standards (New 1986; Indian Standard 1973), PPV is considered as a vibration index, which is a significant indicator to control the structural damage criteria. Several parameters such as blast design, distance from the blast-face, explosive charge weight per delay, and geological conditions are the most effective factors on ground vibration induced by blasting (Wiss and Linehan 1978; Khandelwal and Singh 2007; Iphar et al. 2008).

Various empirical predictors have been suggested for the prediction of PPV (e.g. Duvall and Petkof 1959; Langefors and Kihlstrom 1963; Davies et al. 1964; Ambraseys and Hendron 1968; Roy 1993). Normally, in these approaches, PPVs are obtained from two factors namely maximum charge per delay and distance from the blast-face. As a result, in many cases, these methods are not accurate enough, whereas prediction of the PPV values with high accuracy is important to estimate the blasting safety area. In addition, these empirical equations need to be updated when new blasting data is available. Aside from the empirical equations, the use of statistical methods such as multiple regression analysis in predicting PPV has received attention mainly due to their ease of use (Hudaverdi 2012). However, the implementation of the statistical prediction techniques is not reliable if new available data are different from the original ones (Khandelwal and Singh 2009; Monjezi et al. 2013).

Besides, utilizing artificial intelligence (AI) methods such as artificial neural network (ANN) in the field of earth science is recently highlighted in literatures. This may be attributed to AI capability in solving non-linear continuous functions (Dehghan et al. 2010). Isik and Ozden (2013) used ANN for predicting soil compaction parameters namely maximum dry unit weight 
( dmax) and optimum water content ( opt). Ceryan et al. (2013) conducted a research to predict the uniaxial compressive strength of carbonate rocks using ANN. In another study, Verma and Singh (2013) showed capability of the ANN technique in predicting water quality parameters including biological oxygen demand (BOD) and chemical oxygen demand (COD). Moreover, Park et al. (2013) and Bi et al. (2014) applied ANN to estimate landslide susceptibility index (LSI). Dissolved organic carbon (DOC) in a river network was evaluated and predicted using ANN in the study conducted by Fu et al. (2013). An ANN toolbox was created within GIS software by Lee et al. (2014). They successfully showed capability of this toolbox for solving geotechnical problems. A hybrid ANN-based predictive model was developed to estimate pile bearing capacity in the study carried out by Momeni et al. (2014). Ocak and Seker (2013) utilized ANN technique for solving problem of surface settlement caused by tunneling. A comparative study was performed by Maiti and Tiwari (2014) to predict groundwater level using ANN and adaptive neuro-fuzzy inference system (ANFIS) models. It was found that ANN can perform better than ANFIS for prediction of groundwater level. Gordan et al. (2015) proposed a hybrid particle swarm optimization (PSO)-ANN to predict seismic stability of the homogeneous slopes. Furthermore, several researchers have been used AI techniques in the case of PPV prediction. Khandelwal and Singh (2006) utilized four empirical predictors to estimate the PPV values for 150 blasting operations and obtained results were compared to the measured data. Subsequently, an ANN model was proposed for the prediction of PPV using the same data. They found that ANN results are more accurate compared to empirical predictors. Fisne et al. (2011) used fuzzy inference system (FIS) and regression analysis to predict PPV using 33 datasets obtained from Akdaglar quarry in Turkey. In their research, charge weight and distance from blast-face were considered as model inputs. They concluded that the FIS technique can predict PPV values better than the statistical technique. Monjezi et al. (2013) predicted PPV values using ANN model and the obtained results were compared to the recorded data in Shur River Dam, Iran as well as obtained results by empirical equations. Finally, they concluded that the ANN model has higher 


\section{Case Study and Data Monitoring}

The data used in this study was collected from ISB granite quarry, Kota Tinggi, Johor, Malaysia. The quarry lies geographically in latitude $1^{\circ} 44^{\prime} 12^{\prime \prime}$ Nand longitude $103^{\circ} 54^{\prime} 08^{\prime \prime} \mathrm{E}$, and is located $40 \mathrm{~km}$ north of Johor Bahru (Fig. 1). This quarry supplies granite aggregates for many construction applications with capacity of 37000-44000 ton per month. Depend on the weather condition, 4 to 8 blasting works per month were performed in this site. All blasting operations were performed using blast-hole diameters of $89 \mathrm{~mm}$ and $115 \mathrm{~mm}$. ANFO and dynamite were used as the main explosive material and initiation respectively. The blast-holes were stemmed using fine gravels.

During data collection, blasting parameters including hole diameter, hole depth, maximum charge per delay, burden, spacing, stemming length, powder factor and number of hole were measured. In addition, in each blasting, PPV was monitored using Vibra ZEB seismograph having transducers for PPV measurement. The nearest structure is located about $450 \mathrm{~m}$ to the south of the quarry. It should be mentioned that the distances between monitoring point and blast-face were set in the range of $125 \mathrm{~m}$ to $670 \mathrm{~m}$. Hole depths used in the blasting operations were in the range of $13.5 \mathrm{~m}$ and $26.5 \mathrm{~m}$.In total, 109 blast were recorded and PPV in each blasting operation was monitored. In this study, among all measured blasting parameters, only maximum charge per delay (MC) and distance between monitoring point and blast-face (D) were taken into 
consideration for the prediction of PPV values as recommended by Duvall and Petkof (1959). In addition, the mentioned parameters have been extensively-used as predictor in many PPV prediction studies (see Table 1). Figs. 2-4 show the frequency of measured values of maximum charge per delay, distance between monitoring point and blast-face and PPV, respectively.

\section{Empirical Equation Development}

Numerous PPV equations have been established empirically by many researchers (e.g. Ambraseys and Hendron 1968; Roy 1993). The most popular PPV equation is a typical method suggested by Duvall and Petkof (1959). In the absence of monitoring, the use of scaled distance (SD) factor is a method for prediction of PPV. A relationship between the MC and D values is formed through the SD formula as follows:

$$
\overline{\sqrt{ }}
$$

Where $\mathrm{W}$ is the maximum charge per delay $(\mathrm{kg})$ and $\mathrm{D}$ represents the distance between monitoring point and blast-face (m). Afterward, PPV values can be determined using the suggested equation by Duvall and Petkof (1959) as follows:

In which $B$ and $K$ are site constants. By using measured data from ISB granite quarry and also necessary analysis by SPSS (18.0), an empirical formula was suggested to predict PPV values as:

Coefficient of determination, $\mathrm{R}^{2}$, equals to 0.836 for the Eq. 3 indicates that the proposed empirical equation can predict PPV with suitable accuracy level. Logarithmic graph between monitored PPVs and scaled distance values is shown in Fig. 5.

\section{Artificial Intelligence Techniques for PPV Prediction}

\subsection{Artificial Neural Network (ANN)}


ANNs are information processing patterns simulating the biological nervous systems which figure out the existing function from actual data. In other words, an ANN is a flexible non-linear function approximation that estimates a relationship between given input and output parameters. ANNs learn by examples in order to obtain a connection through the parameters. The earliest neuron was introduced by McCulloch and Pitts (1943), called the “Threshold Logic Unit”. Their model describes a neuron as a linear threshold, equivalent to using the unit step function; the function value is 0 , if the nerve cell remains inactive, or 1 , if the cell fires. Nevertheless, the first ANN was developed by Rosenblatt (1958), called the "perceptron" based on the neuron of McCulloch and Pitts (1943).

ANNs are composed of a set of parallel interconnected processing units titled nodes or neurons. There is an activation function along each neuron which transfers the activation signal between nodes. However, the ability of an ANN in data processing is mainly related to its architecture and weights (Dreyfus 2005; Engelbrecht 2007). In terms of the structure, ANNs are divided into two types; feed-forward and recurrent ANNs. In feed-forward ANNs, the neurons are usually classified into several layers. Using the connections, a signal moves throughout the input to the output layer(s). Multi-layer perceptron (MLP) is the most well-known type of feed-forward ANNs (Kosko 1994). In recurrent ANNs, the outputs of some (or all) neurons are fed back to the same neuron or into neurons in preceding layers. Therefore, the signals can move both forward and backward. Compared to other types of ANNs, feed forward MLP ANN is not complicated to implement (Bounds et al. 1998). This type of ANN has been applied successfully in various areas of engineering problems (Meulenkamp and Grima 1999; Singh et al. 2001; Tonnizam Mohamad et al. 2014).

The ability of ANNs to learn from samples and improve their performance is obtained by learning algorithm. Back-propagation (BP) algorithm is the most common training algorithm that tries to adjust the network weights during learning process by reducing the error between input and 
output data (Specht 1991). Fundamentally, BP learning consists of forward and backward passes in various layers of the network. The input parameters are applied to the hidden neurons and subsequently the outputs are produced. The error correction is conducted if the outputs of the network are different from the desired values. This action is conducted through the adjustment of weights and biases in which BP algorithm utilized for this purpose (Basheer and Hajmeer 2000). Eventually, the system error can be computed based on some performance criteria such as root mean square error (RMSE) (Kosko 1994; Simpson 1990).

\subsection{PPV Prediction by ANN}

As mentioned previously, maximum charge per delay and distance between monitoring point and blast-face were considered as model inputs for prediction of PPV values. More detail of the input and output parameters are shown in Table 2. In this study, all datasets were normalized by using following equation:

$\mathrm{Xnorm}=(\mathrm{X}-\mathrm{Xmin}) /(\mathrm{Xmax}-\mathrm{Xmin})$

Where $\mathrm{X}$ is the measured value, $\mathrm{Xnorm}$ is the normalized value of the measured parameter; $\mathrm{Xmin}$ and Xmax are the minimum and maximum values of the measured parameters in the dataset, respectively. Afterwards, all 109 datasets were divided into training and testing datasets. In this regard, $80 \%$ of the datasets were assigned for training purposes while the other $20 \%$ was used for testing of the network performance. To achieve the premier ANN performance, optimal network architecture should be determined. Hornik et al. (1989) stated that only one hidden layer in the network architecture can estimate any continuous function. Hence, in this study, one hidden layer was used. Aside from the number of hidden layer, in ANN architecture, selecting the number of nodes in the hidden layer is the most critical task (Sonmez et al. 2006). Many relations have been established to determine the number of nodes in hidden layers by some scholars as it can be seen in Table 3. According to this table, using two inputs and one output, the number of nodes which should be used in the hidden layer varies between one and six. In the next step of the analysis, the 
optimum number of nodes in the hidden layer must be determined. For this purpose, several networks with one hidden layer were trained and tested to predict PPV values as shown in Table 4. As tabulated in this table, each model was repeated five times by using the random distributions of datasets. In this table, results in terms of RMSE are listed for training and testing datasets, whereas RMSE values for testing datasets were set as performance criteria. Model number 6 with six hidden nodes (second iteration) indicates higher prediction performance compared to other models in predicting PPV. Therefore, this model with two inputs, one hidden layer and six nodes in the hidden layer was selected as the best ANN model. It is also worth mentioning that in construction of ANN models, the learning rate and momentum coefficient were set to be 0.1 and 0.9 respectively.

\subsection{Adaptive Neuro-Fuzzy Inference System}

The adaptive neuro-fuzzy inference system (ANFIS) was first introduced by Jang (1993). Study by Jung et al. (1997) recommends ANFIS capability in approximating any actual continuous function. ANFIS is capable of simulating a functional mapping which approximates the prediction process of the internal system parameter. The term neuro-fuzzy is used due to the fact that in this artificial intelligence methods, the FIS concept is integrated into the ANN. Many researchers have addressed the successful application of ANFIS in solving geotechnical problems (Grima et al. 2000; Singh et al. 2012; Yesiloglu-Gultekin et al. 2013; Jahed Armaghani et al. 2014). In fact, the prime objective of ANFIS is to map a relationship between the input and output parameters. This can be done through a hybrid learning procedure for determination of the membership function (MF) distribution. A classic ANFIS network architecture comprising two input parameters $\mathrm{x}, \mathrm{y}$ and a single output parameter $\mathrm{f}$ is presented in Fig. 6. As shown in this figure, the architecture consists of multiple layers i.e. 5 in the inference system, and each layer includes a number of neurons, which are defined by the neuron function. 
In the previous layers, the output node is recognized as the feeding data of the present layer. After applying an operation using neuron function in the present layer, the model output forms the input signals of the next layer. To briefly illustrate the ANFIS procedure, consider a FIS model comprising, $x$ and $y$ as inputs and $f$ as output. Hence, two fuzzy 'if-then'” rules can be introduced as shown in the following lines:

(rule 1)

(rule 2)

where, $A_{1}, A_{2}, B_{1}, B_{2}$ are defined as MFs for inputs $x$ and $y ; p_{1}, q_{1}, r_{1}, p_{2}, q_{2}, r_{2}$ are the output function parameters. In the following, the five-layer ANFIS comprising two fuzzy rules, $x$ and $y$ (inputs) and one output ( $f$ ) is discussed (Jang 1993):

Layer 1: All neurons $i$ in this layer are adaptive neurons.

$$
\begin{aligned}
& O_{1, i}=\mu A_{i}(x) \\
& O_{1, i}=\mu B_{i}(y)
\end{aligned}
$$

For ri=1, 2 where $x$ and $y$ are set as input nodes, and $A$ and $B$ are the linguistic labels. Also, $\mu A_{i}(x)$ and $\mu B_{i}(y)$ symbolize the MFs.

Layer 2: The neurons are labeled $\Pi$ and shown by a circle. The output node, then, is formed based on incoming signals.

$$
O_{2, i}=\omega_{i}=\mu A_{i}(x) \mu B_{i}(y) \text { with } i=1,2
$$

The output node $\omega_{i}$ indicates the firing strength of a rule.

Layer 3: Every neuron in this layer is a fixed neuron to be identified by a circle and labeled as N. The output is obtained based on the ratio of the $i^{\text {th }}$ rule's firing strength over the summation of firing strength of all rules. 


$$
O_{3, i}=\varpi_{i}=\omega_{i} /\left(\omega_{1}+\omega_{2}\right) \text { with } \mathrm{i}=1,2
$$

Layer 4: In this layer, every neuron is an adaptive neuron with the neuron function like this:

$$
O_{4, i}=\varpi_{i} f_{i}=\varpi_{i}\left(p_{i} X+q_{i} y+r_{i}\right)
$$

Where parameters $p_{i}, q_{i}, r_{i}$ are typically known as consequent parameters and $\varpi_{i}$ denotes normalized firing strength.

Layer 5: In this layer the final step is taken. This step deals with generating the output amount through summation of all incoming signals:

$$
O_{5, i}=\sum_{i} \varpi_{i} f_{i}=\sum_{i} \varpi_{i} f_{i} / \sum_{i} \varpi_{i} ; \quad i=1,2
$$

Back-propagation gradient descent forms the basic training rule of ANFIS. In this learning algorithm, the error signals from the output layer backward to the input neuron are recursively determined. Based on the architecture presented in Fig. 6 (b), the output ( $f$ ) can be presented as a linear group of the consequent parameters. To learn the fuzzy model employing differentiable functions, ANFIS employ a hybrid-learning rule due to its ease of use. The conventional BP algorithm is mainly utilized by ANFIS to train the MF parameters. Also, the classic least-squares predictor is applied by ANFIS to train the parameter of the first-order polynomial of the TakagiSugeno-Kang fuzzy model as stated in a study by Jang et al. (1997).

The hybrid training algorithm of ANFIS uses so-called forward and backward passes. In the former, functional signals go forward till layer 4 and the consequent parameters are estimated using least-squares error criteria. Subsequently, like ANN procedure, to update the premise parameters, the obtained errors are backwardly propagated. This process is repeated using gradient descendent method until reaching a desirable output. The final output can be illustrated in the following manner: 
where $p_{1}, q_{1}, r_{1}, p_{2}, q_{2}$, and $r_{2}$ are consequent parameters. The prime advantage of implementing an ANFIS model is efficient determination of the consequent and optimal premise parameters during training procedure.

\subsection{PPV Prediction by ANFIS}

This paper provides an insight into the application of ANFIS for predicting PPV. Similar to ANN part, the required datasets for modelling were randomly divided into two subsets: $80 \%$ of the dataset was set for training the model and the rest was considered for testing purposes. In this study, the numbers of fuzzy rules were determined using a trial-error method. Numerous models with different fuzzy rule combinations (e.g. 2, 3 and so on) were used for this reason. Eventually, it was concluded that the ANFIS structure with 5MFs for each input performs best when the results of RMSE were compared. In overall, the conducted parametric study suggested that the best prediction performance of the model is expected when ANFIS model is trained with 25 fuzzy roles (5 5). The type of MF utilized for each input is the Gaussian MF. Gaussian MFs are the most well-known MF in the literatures of fuzzy system, as they provide both simplicity and flexibility (Tutmez et al. 2007). In the next step of the modeling, ANFIS models were built to predict PPV values. Prediction performances of these models are shown in Table 5. This table indicates that PPV values were repeated 5 times using different training and testing datasets randomly. According to the presented results in this table, model number 4 outperforms other models. Hence, the aforementioned model i.e. model number 4 was chosen for prediction of PPV.

RMSE values equal to 0.983 and 1.017 for training and testing datasets show the high performance capacity of the ANFIS model in predicting PPV. In model number 4, the MFs of the inputs were adjusted after 29,700 epochs using the hybrid optimization method. This optimization 
method includes BP for the parameters associated with the input MFs and also estimation of least-squares for the parameters associated with the output MFs.

Figs.7 and 8 display the assigned input MFs after training step. The linguistic variables assigned for "'maximum charge weight per delay”' and “distance”, are very low (VL), low (L), medium $(\mathrm{M})$, high $(\mathrm{H})$, very high $(\mathrm{VH})$, and very close $(\mathrm{VC})$, close $(\mathrm{C})$, normal $(\mathrm{N})$, far $(\mathrm{F})$, very far $(\mathrm{VF})$, respectively. Additionally, the type of output membership function was set to be linear. It should be mentioned that all ANN and ANFIS predictive models were constructed using MATLAB (version 7.14.0.739). SPSS package (18.0) was used to determine RMSE values as well as statistical calculations. The suggested ANFIS structure is shown in Fig. 9.

\section{Results and Discussion}

In this study, an attempt has been made to examine the ability of ANN and ANFIS models for prediction of PPV values induced by quarry blasting. For this purpose, a database comprising of 109 blasting operations was prepared. Several ANN and ANFIS models were built using two inputs namely maximum charge per delay and the distance from the blast-face. Additionally, using the same datasets based on suggested method by Duvall and Petkof (1959), an empirical equation was proposed. Fig. 10 shows the PPV values predicted by empirical equation against monitored PPVs. $\mathrm{R}^{2}$ value equal to 0.836 reveals that this equation is able to predict PPV with suitable accuracy. Fig. 11 displays the predicted PPVs by employing conventional ANN technique plotted against the measured PPV values for training and testing datasets. The $\mathrm{R}^{2}$ values of 0.955 and 0.902 for training and testing datasets show that the ANN approach can predict PPV with high accuracy level. Moreover, in the prediction of PPV using the ANFIS technique, $\mathrm{R}^{2}$ values of 0.974 and 0.969 for training and testing datasets suggest the superiority of this technique in predicting PPV compared to proposed empirical equation and ANN technique (see Fig. 12). 
Where $y$ and $y^{\prime}$ are the obtained and predicted values, respectively and $N$ is the total number of data. When the RMSE value is zero and VAF value is 100, the model `s performance is perfect. Table 7 shows the performance indices achieved by all mentioned models in this study. As it can be seen in this table, the ANFIS model can provide higher performance capacity in predicting PPV induced by blasting compared to other predictive techniques. The values of $0.973,0.987$ and 97.345 for $\mathrm{R}^{2}$, RMSE and VAF respectively reveal that the ANFIS model is capable to predict PPV with high degree of accuracy. It is important to note that proposed model based on USBM in this study can predict PPV values better than empirical PPV predictors. This can be seen clearly based on obtained RMSE values. RMSE value of 2.469 for proposed model based on USBM shows superiority of this model in predicting PPV, while these values were obtained as 10.473, 6.391, 7.821, 6.233 and 4.078 for Langefors - Kihlstrom, general predictor, Indian standard, Ghosh - Daemen predictor, and CMRI models, respectively. The presented results show that all 


\section{Conclusions}

In this study, several models have been proposed to predict ground vibration induced by quarry blasting. The model dataset include blasting parameters and PPV values of 109 blasting works in ISB granite quarry, Johor, Malaysia. The maximum charge per delay and distance from blast-face were considered as model inputs for prediction of PPVs. Several ANN and ANFIS models were trained and tested using the mentioned inputs-output configuration and finally two models were chosen as best models of ANN and ANFIS. Apart from that, using the same input parameters, a model based on USBM was proposed for prediction of PPV values. To show the ability of the proposed models, some empirical predictors were also applied to predict PPVs. Finally, the results indicated that the ANFIS predictive model is able to predict PPVs with higher accuracy compared to other models. It is worth noting that in practice all proposed methods have the applicability of PPV prediction. However, depending on the condition, they should be used accordingly.

\section{Acknowledgement}

The authors would like to extend their appreciation to the Universiti Teknologi Malaysia for all facilities that made this research possible.

\section{References}

Ambraseys NR, Hendron AJ (1968) Dynamic Behavior of Rock Masses: Rock Mechanics in Engineering Practices. London: Wiley

Basheer IA, Hajmeer M (2000) Artificial neural networks: fundamentals, computing, design, and application. J Microbiol Meth 43:3-31 
Bi R, Schleier M, Rohn J, Ehret D, Xiang W (2014) Landslide susceptibility analysis based on ArcGIS and Artificial Neural Network for a large catchment in Three Gorges region, China. Environ Earth Sci 72(6):1925-1938

Bounds DG, Lloyd PJ, Mathew B, Waddell G (1998) A multilayer perceptron network for the diagnosis of low back pain In Neural Networks. IEEE International Conference 481-489

Bureau of Indian Standard (1973) Criteria for safety and design of structures subjected to underground blast. ISI Bull IS-6922

Ceryan N, Okkan U, Kesimal A (2013) Prediction of unconfined compressive strength of carbonate rocks using artificial neural networks. Environ Earth Sci 68(3):807-819

Davies B, Farmer IW, Attewell PB (1964) Ground vibrations from shallow sub-surface blasts. The Engineer 217: 553-559

Dehghan S, Sattari GH, Chehreh CS, Aliabadi MA (2010) Prediction of unconfined compressive strength and modulus of elasticity for Travertine samples using regression and artificial neural. New Min Sci Technol 20:0041-0046

Dowding CH (1985) Blast vibration monitoring and control. Englewoods Cliffs, NJ: Prentice-Hall pp, 288290

Dreyfus G (2005) Neural Networks: methodology and application. (2 ${ }^{\text {nd }}$ ed.), Springer, Berlin Heidelberg, Germany

Duvall WI, Petkof B (1959) Spherical Propagation of Explosion Generated Strain Pulses in Rock. USBM Report of Investigation 5483, 21

Ebrahimi E, Monjezi M, Khalesi MR, Jahed Armaghani D (2015) Prediction and optimization of backbreak and rock fragmentation using an artificial neural network and a bee colony algorithm. Bull Eng Geol Environ DOI 10.1007/s10064-015-0720-2

Engelbrecht AP (2007) Computational intelligence: an introduction. John Wiley \& Sons 
Fisne A, Kuzu C, Hüdaverdi T (2011) Prediction of environmental impacts of quarry blasting operation using fuzzy logic. Environ Monit Assess 174:461-470

Fu Y, Zhao Y, Zhang Y, Guo T, He Z, Chen J (2013) GIS and ANN-based spatial prediction of DOC in river networks: a case study in Dongjiang, Southern China. Environ Earth Sci 68(5):1495-1505

Ghasemi E, Ataei M, Hashemolhosseini H (2013) Development of a fuzzy model for predicting ground vibration caused by rock blasting in surface mining. J Vib Control 19(5):755-770

Ghoraba S, Monjezi M, Talebi N, Moghadam MR, Jahed Armaghani D (2015) Prediction of ground vibration caused by blasting operations through a neural network approach: a case study of Gol-EGohar Iron Mine, Iran. J Zhejiang University Sci A doi:10.1631/jzus.A1400252

Gordan B, Jahed Armaghani D, Hajihassani M, Monjezi M (2015) Prediction of seismic slope stability through combination of particle swarm optimization and neural network. Eng Comput doi:10.1007/s00366-015-0400-7

Grima MA, Bruines PA, Verhoef PNW (2000) Modeling tunnel boring machine performance by neurofuzzy methods. Tunn Undergr Sp Technol 15(3):260-269

Hajihassani M, Jahed Armaghani D, Sohaei H, Tonnizam Mohamad E, Marto A (2014a) Prediction of airblast-overpressure induced by blasting using a hybrid artificial neural network and particle swarm optimization. Appl Acoust 80:57-67

Hajihassani M, Jahed Armaghani D, Marto A, Tonnizam Mohamad E (2014b) Ground vibration prediction in quarry blasting through an artificial neural network optimized by imperialist competitive algorithm. Bull Eng Geol Environ doi: 10.1007/s10064-014-0657-x

Hecht-Nielsen R (1987) Kolmogorov's mapping neural network existence theorem. Proceedings of the first IEEE international conference on neural networks, San Diego CA, USA, pp 11-4

Hornik K, Stinchcombe M, White H (1989) Multilayer feedforward networks are universal Approximators. Neural Networks 2:359-366 
Hudaverdi T (2012) Application of multivariate analysis for prediction of blast-induced ground vibrations. Soil Dyn Earthq Eng 43:300-308

Hush DR (1989) Classification with neural networks: a performance analysis. Proceedings of the IEEE international conference on systems Engineering Dayton Ohia, USA, pp 277-80

Iphar M, Yavuz M, Ak H (2008) Prediction of ground vibrations resulting from the blasting operations in an open-pit mine by adaptive neuro-fuzzy inference system. Environ Geol 56(1):97-107

Isik F, Ozden G (2013) Estimating compaction parameters of fine-and coarse-grained soils by means of artificial neural networks. Environ Earth Sci 69(7):2287-2297

Jahed Armaghani D, Tonnizam Mohamad E, Momeni E, Narayanasamy MS, Mohd Amin MF (2014) An adaptive neuro-fuzzy inference system for predicting unconfined compressive strength and Young’s modulus: a study on Main Range granite. Bull Eng Geol Environ doi:10.1007/s10064014-0687-4

Jahed Armaghani D, Hajihassani M, Mohamad ET, Marto A, Noorani SA (2013) Blasting-induced flyrock and ground vibration prediction through an expert artificial neural network based on particle swarm optimization. Arab J Geosci doi:10.1007/s12517-013-1174-0

Jang RJS (1993) Anfis: adaptive-network-based fuzzy inference system. IEEE Trans Syst Man Cybern 23:665-685

Jang RJS, Sun CT, Mizutani E (1997) Neuro-fuzzy and soft computing. Prentice-Hall, Upper Saddle River, p 614

Kaastra I, Boyd M (1996) Designing a neural network for forecasting financial and economic time series. Neurocomputing 10:215-36

Kanellopoulas I, Wilkinson GG (1997) Strategies and best practice for neural network image classification. Int J Remote Sensing 18:711-25

Khandelwal M, Singh TN (2009) Prediction of blast-induced ground vibration using artificial neural network. Int J Rock Mech Min Sci 46:1214-1222 


\begin{abstract}
Khandelwal M, Kumar DL, Yellishetty M (2011) Application of soft computing to predict blast-induced ground vibration. Eng Comput 27(2):117-125
\end{abstract}

Khandelwal M, Singh TN (2006) Prediction of blast induced ground vibrations and frequency in opencast mine-a neural network approach. J Sound Vib 289:711-725

Khandelwal M, Singh TN (2007) Evaluation of blast-induced ground vibration predictors. Soil Dyn Earthq Eng 27(2):116-125

Kosko B (1994) Neural networks and fuzzy systems: a dynamical systems approach to machine intelligence. Prentice Hall: New Delhi

Langefors U and Kihlstrom B (1963) The modern technique of rock blasting. New York: Wiley

Lee S, An H, Yu S, Oh JJ (2014) Creating an advanced backpropagation neural network toolbox within GIS software. Environ Earth Sci 72(8):3111-3128

Li DT, Yan JL, Zhang L (2012) Prediction of Blast-Induced Ground Vibration Using Support Vector Machine by Tunnel Excavation. Appl Mech Mater 170:1414-1418

Masters T (1994) Practical neural network recipes in C++. Boston MA: Academic Press

Maiti S, Tiwari RK (2014) A comparative study of artificial neural networks, Bayesian neural networks and adaptive neuro-fuzzy inference system in groundwater level prediction. Environ Earth Sci 71(7):3147-3160

McCulloch WS, Pitts W (1943) A logical calculus of the ideas immanent in nervous activity. Bull Math Biophys J 5:115-133

Meulenkamp F, Grima MA (1999) Application of neural networks for the prediction of the unconfined compressive strength (UCS) from Equotip hardness. Int J Rock Mech Min Sci 36(1):29-39

Mohamed MT (2011) Performance of fuzzy logic and artificial neural network in prediction of ground and air vibrations. Int J Rock Mech Min Sci 48(5):845-851 
Mohamadnejad M, Gholami R, Ataei M (2012) Comparison of intelligence science techniques and empirical methods for prediction of blasting vibrations. Tunn Undergr Sp Technol 28:238-244

Momeni E, Nazir R, Jahed Armaghani D, Maizir H (2014) Prediction of Pile Bearing Capacity Using a Hybrid Genetic Algorithm-Based Ann. Measurement 57:122-131

Monjezi M, Ahmadi M, Sheikhan A, Bahrami M, Salimi AR (2010) Predicting blast-induced ground vibration using various types of neural networks. Soil Dyn Earthq Eng 30:1233-1236

Monjezi M, Hasanipanah M, Khandelwal M (2013) Evaluation and prediction of blast-induced ground vibration at Shur River Dam, Iran, by artificial neural network. Neural Comput Appl 22:16371643

Monjezi M, Ghafurikalajahi M, Bahrami A (2011) Prediction of blast-induced ground vibration using artificial neural networks. Tunn Undergr Sp Technol 26(1):46-50

New BM (1986) Ground vibration caused by civil engineering works.Transport and Road Research Laboratory Research Report, 53, 19

Ocak I, Seker SE (2013) Calculation of surface settlements caused by EPBM tunneling using artificial neural network, SVM, and Gaussian processes. Environ Earth Sci 70(3):1263-1276

Ozer U, Kahriman A, Aksoy M, Adiguzel D, Karadogan A (2008) The analysis of ground vibrations induced by bench blasting at Akyol quarry and practical blasting charts. Environ Geol 54:737-43

Paola JD (1994) Neural network classification of multispectral imagery. MSc thesis, The University of Arizona, USA

Park S, Choi C, Kim B, Kim J (2013) Landslide susceptibility mapping using frequency ratio, analytic hierarchy process, logistic regression, and artificial neural network methods at the Inje area, Korea. Environ Earth Sci 68(5):1443-1464

Raina AK, Murthy VMSR, Soni AK (2014) Flyrock in bench blasting: a comprehensive review. Bull. Eng. Geol Environ doi:10.1007/s10064-014-0588-6 
Ripley BD (1993) Statistical aspects of neural networks. In: Barndoff- Neilsen OE, Jensen JL, Kendall WS, editors. Networks and chaos-statistical and probabilistic aspects. London: Chapman \& Hall, pp 40123

Roy PP (1993) Putting ground vibration predictors into practice. J Colliery Guardian 241:63-67

Rosenblatt F (1958) The perceptron: a probabilistic model for information storage and organization in the brain. Psychological Review 65:386

Simpson PK (1990) Artificial neural system: foundation, paradigms applications and implementations. New York, Pergamon

Singh TN and Singh V (2005) An intelligent approach to prediction and control ground vibration in mines. Geotech Geolog Eng 23:249-262

Specht DF (1991) A general regression neural network Neural Networks. IEEE Transactions 2:568-576

Sonmez H, Gokceoglu C, Nefeslioglu HA, Kayabasi A (2006) Estimation of rock modulus: for intact rocks with an artificial neural network and for rock masses with a new empirical equation. Int J Rock Mech Min Sci, 43:224-235

Singh R, Kainthola A, Singh TN (2012) Estimation of elastic constant of rocks using an ANFIS approach. Appl Soft Comput 12(1):40-45

Singh VK, Singh D, Singh TN (2001) Prediction of strength properties of some schistose rocks from petrographic properties using artificial neural networks. Int J Rock Mech Min Sci 38(2):269-284

Tonnizam Mohamad E, JahedArmaghani D, Momeni E, AlaviNezhad Khalil Abad SV (2014) Prediction of the unconfined compressive strength of soft rocks: a PSO-based ANN approach. Bull EngGeol Environ doi:10.1007/s10064-014-0638-0

Tutmez B, Dag A, Tercan AE, Kaymak U (2007) Lignite thicknessestimation via adaptive fuzzy-neural network. In: 20th internationalmining congress and exhibition of Turkey-IMCET2007,Ankara, 68 June 2007 
Verma AK, Singh TN (2013) Prediction of water quality from simple field parameters. Environ Earth Sci 69(3):821-829

Wang C (1994) A theory of generalization in learning machines with neural application. PhD thesis, The University of Pennsylvania, USA

Wiss JF, Linehan PW (1978) Control of vibration and air noise from surface coal Mines-III. US Bureau of Mines Report OFR 103(3)-79, p 623

Yesiloglu-Gultekin N, Gokceoglu C, Sezer EA (2013) Prediction of uniaxial compressive strength of granitic rocks by various nonlinear tools and comparison of their performances. Int J Rock Mech Min Sci 62:113-122 


\section{List of Figures:}

Fig. 1 Map view of Kota Tinggi

Fig. 2 Frequency histogram of measured MC values

Fig. 3 Frequency histogram of measured D values

Fig. 4 Frequency histogram of monitored PPV values

Fig. 5 PPV values against scaled distance

Fig. 6 (a) Sugeno fuzzy model with two rules, (b) equivalent ANFIS architecture [54]

Fig. 7 Assigned MF for maximum charge per delay

Fig. 8 Assigned MF for distance between monitoring point and blast-face

Fig. 9 Suggested ANFIS structure for PPV prediction

Fig. 10 PPV values obtained by proposed empirical equation versus the measured PPVs

Fig. $11 \mathrm{R}^{2}$ values of measured and predicted PPV values for training and testing datasets using ANN

Fig. $12 \mathrm{R}^{2}$ values of measured and predicted PPV values for training and testing datasets using ANFIS

Fig. 13 Measured PPVs against predicted PPVs by Langefors - Kihlstrom (1963)

Fig. 14 Measured PPVs against predicted PPVs by general predictor by Davies et al. (1964)

Fig. 15 Measured PPVs against predicted PPVs by Bureau of Indian standard (1973)

Fig. 16 Measured PPVs against predicted PPVs by Ghosh - Daemen predictor (1983)

Fig. 17 Measured PPVs against predicted PPVs by CMRI by Roy (1993) 


\section{List of Tables:}

Table 1 Recent works on PPV prediction using soft computation techniques

Table 2 Parameters used in the predictive model with their categories

Table 3 Recommended number of nodes for hidden layers [44]

Table 4 Performances of trained ANN models to predict PPV

Table 5 Performances of the 5 ANFIS models in predicting PPV

Table 6 Empirical PPV models

Table 7 Performance indices of all utilized models for prediction of PPV 


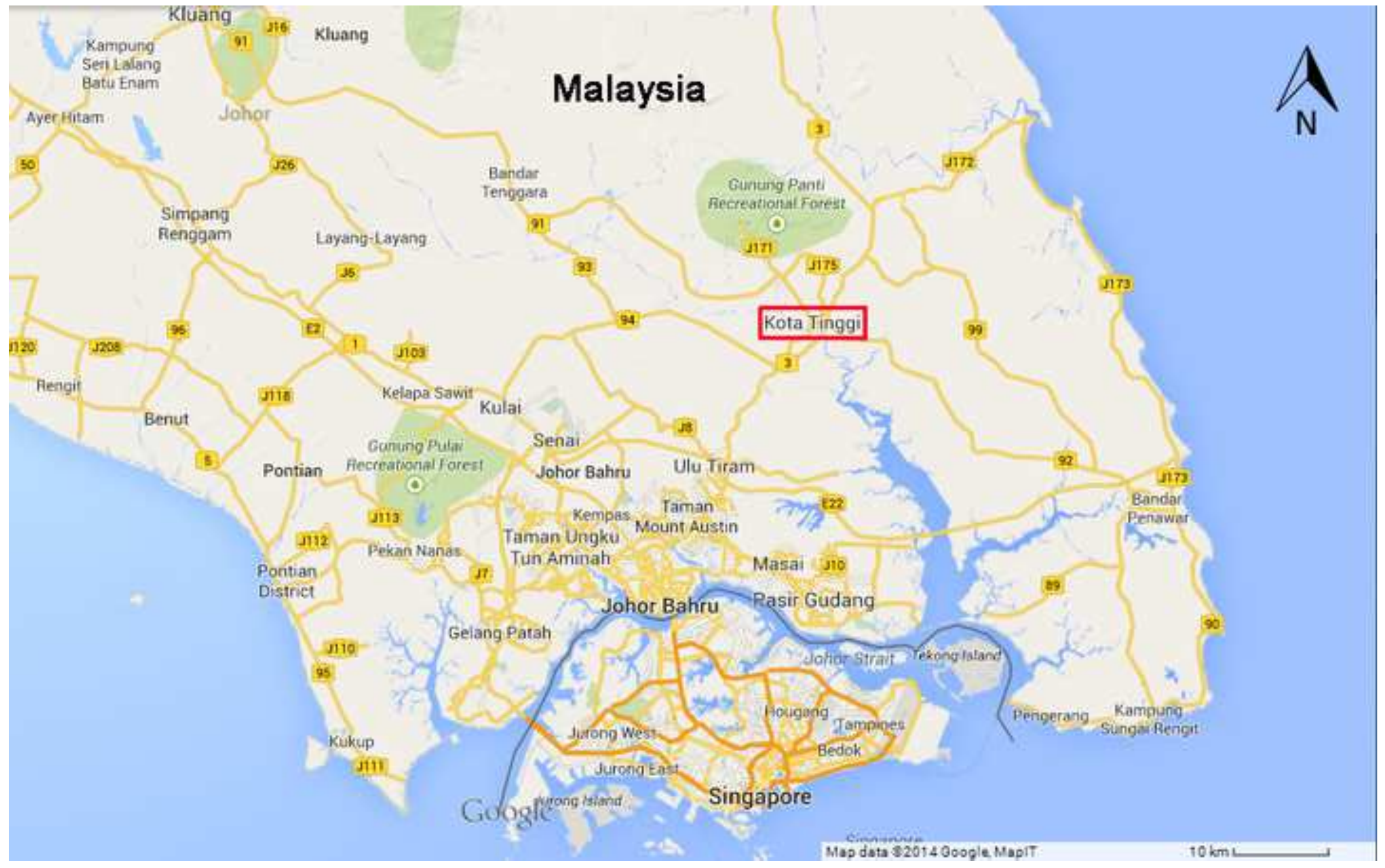




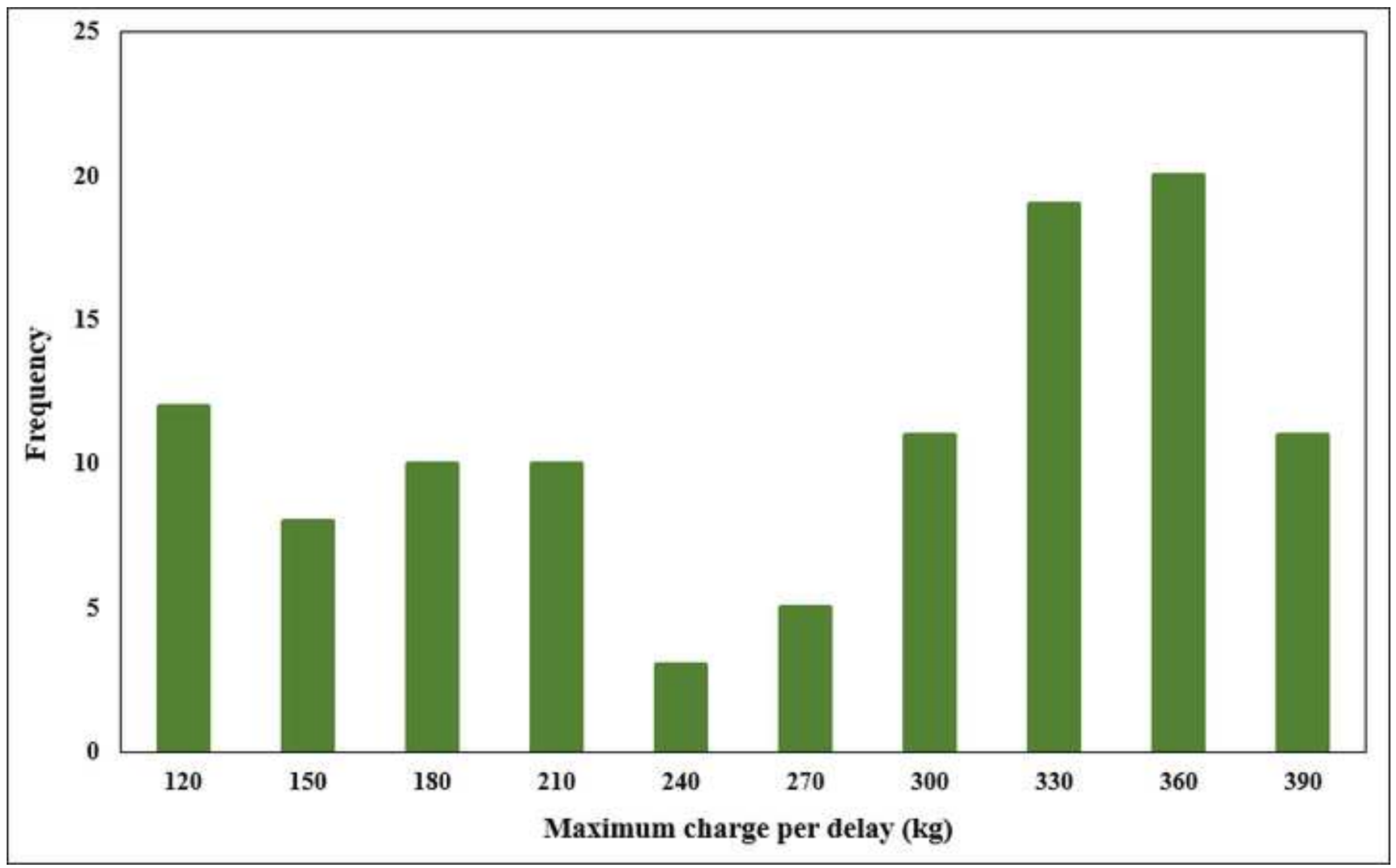


Click here to download high resolution image

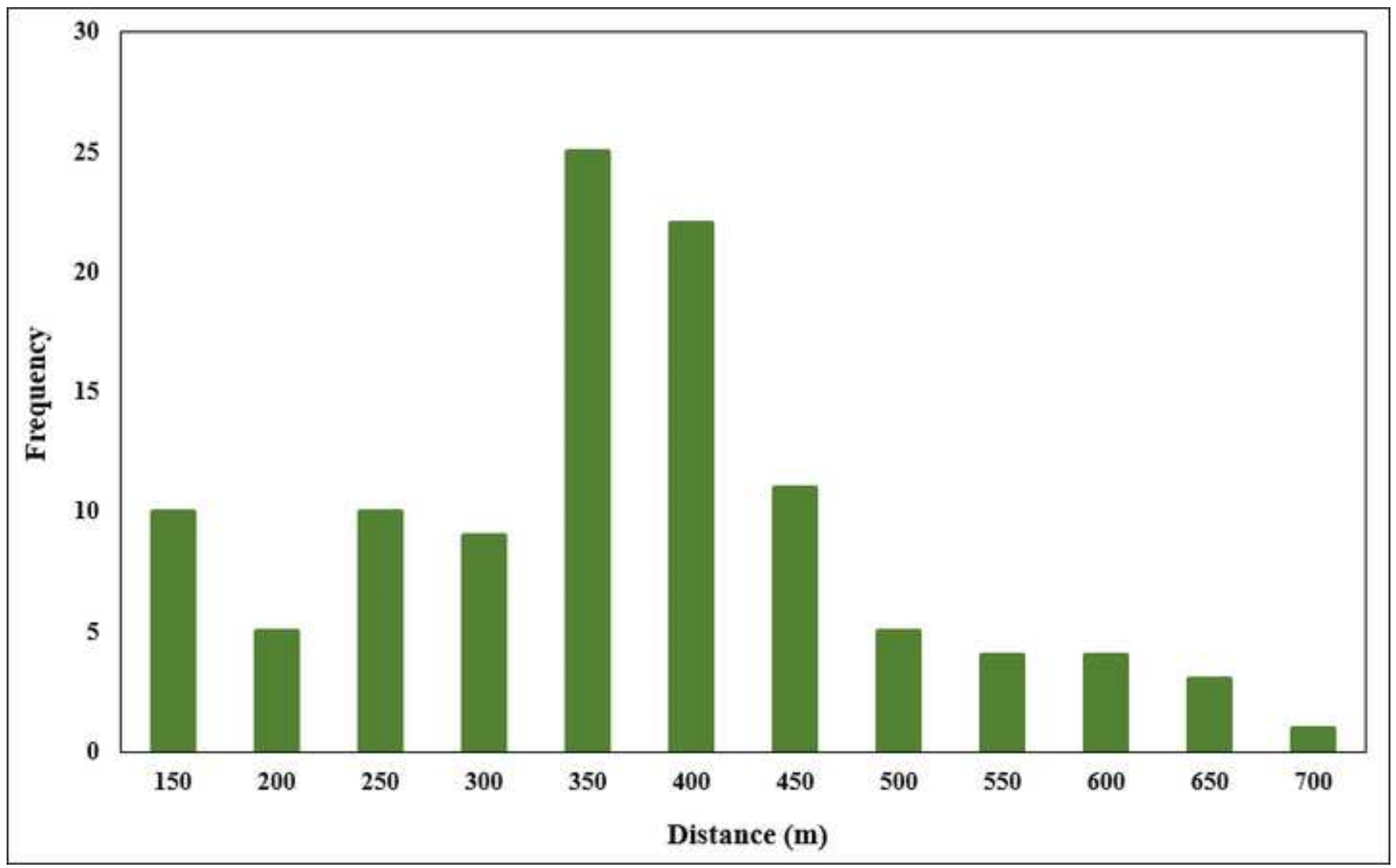




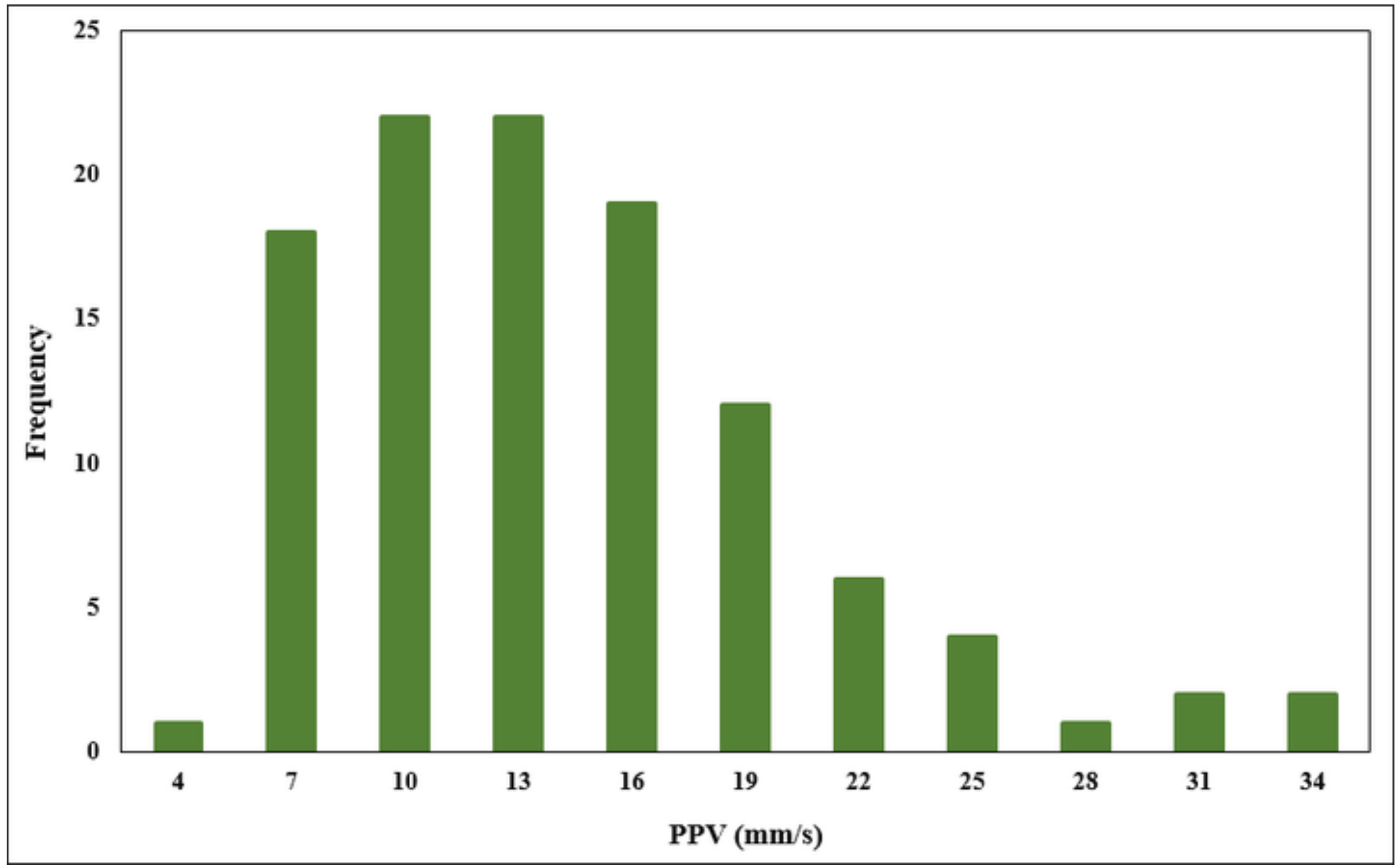




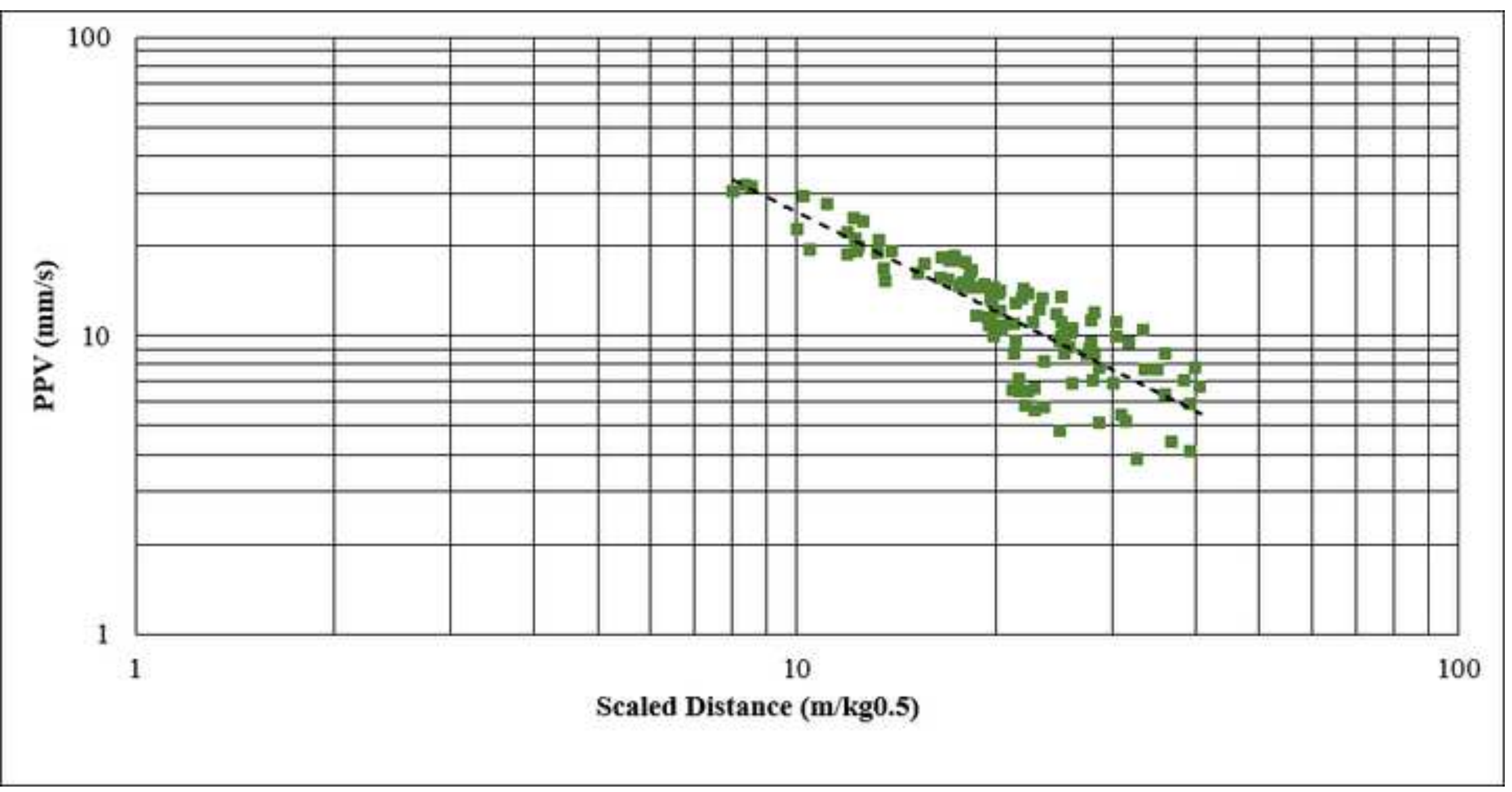




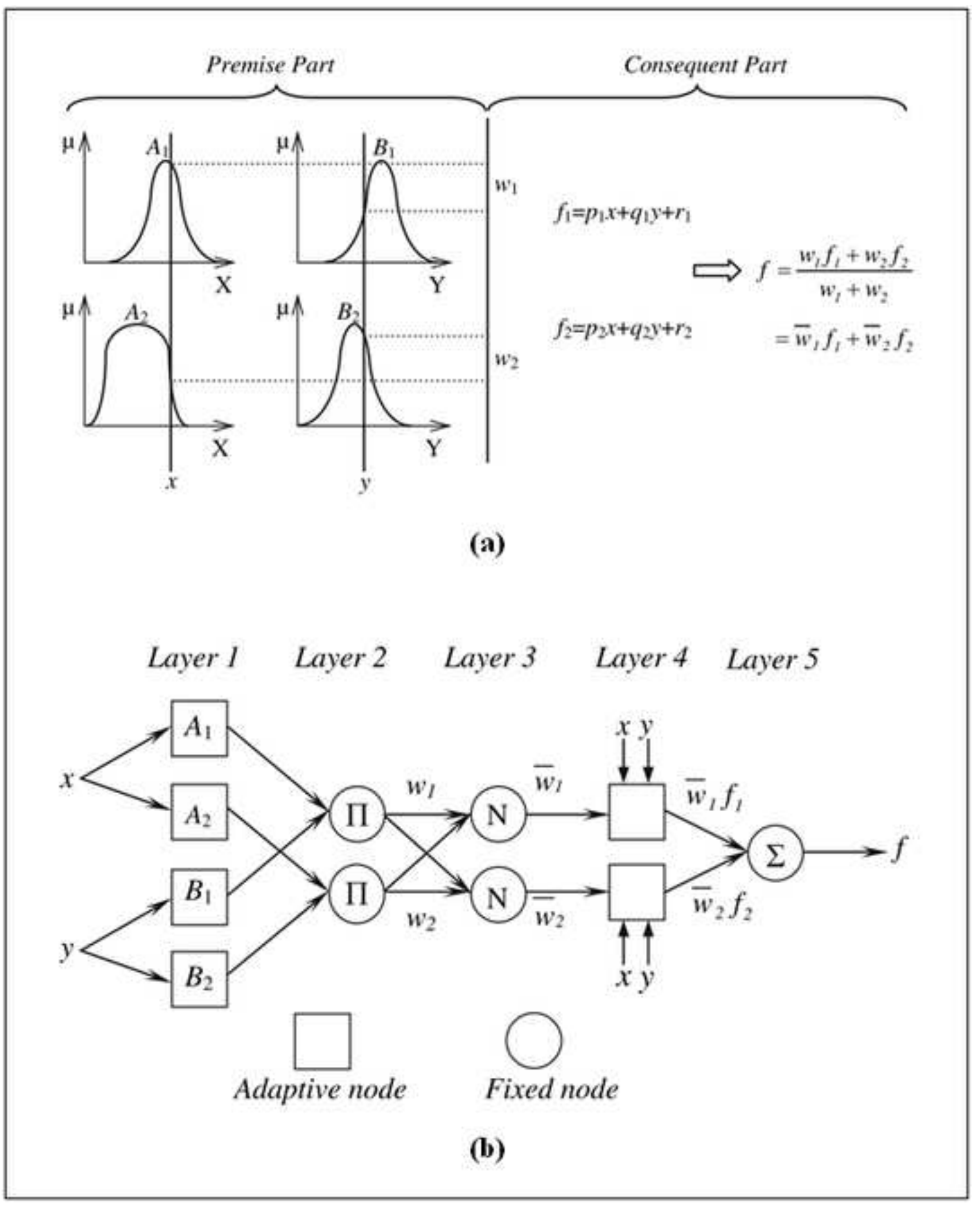




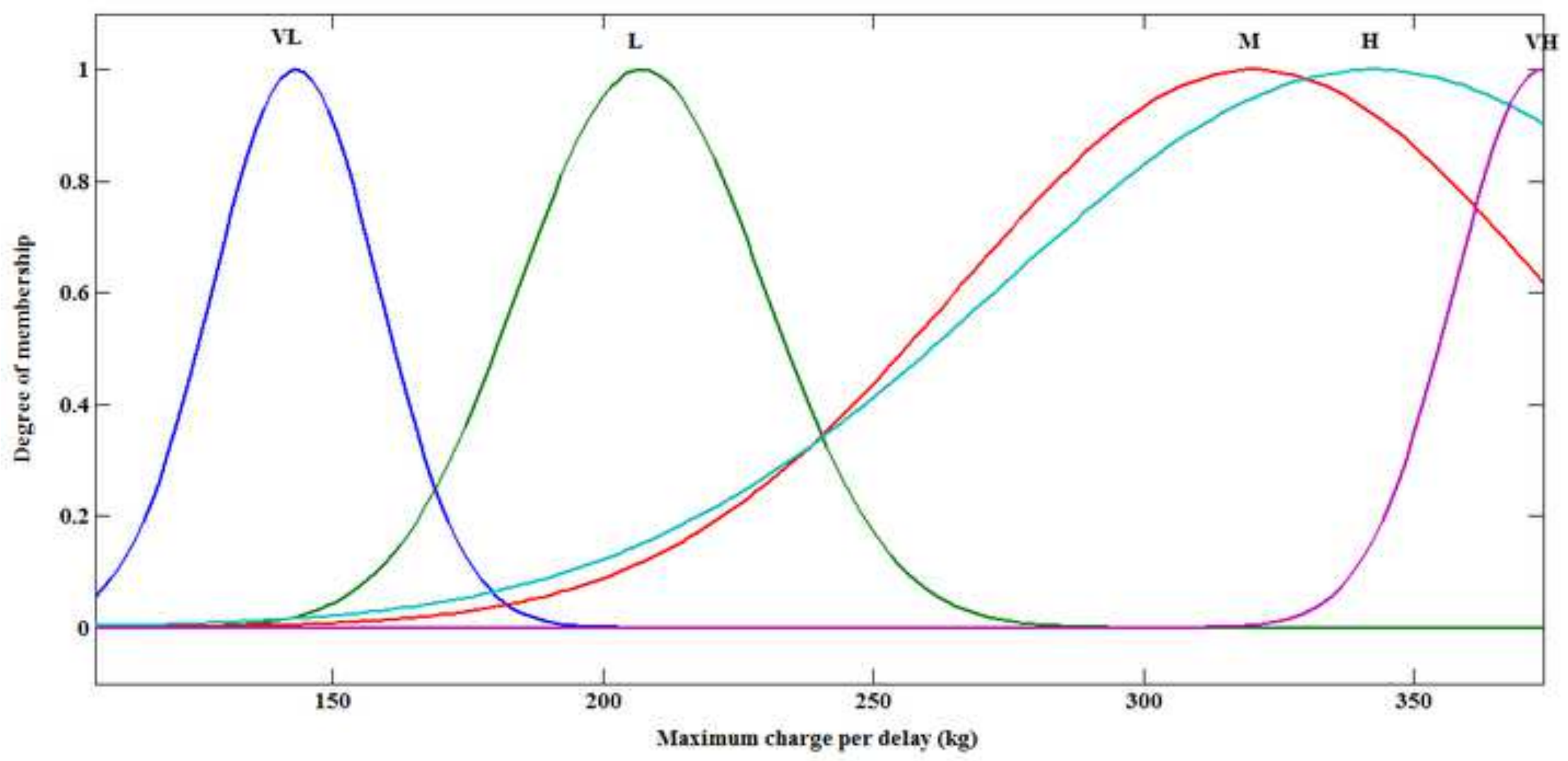




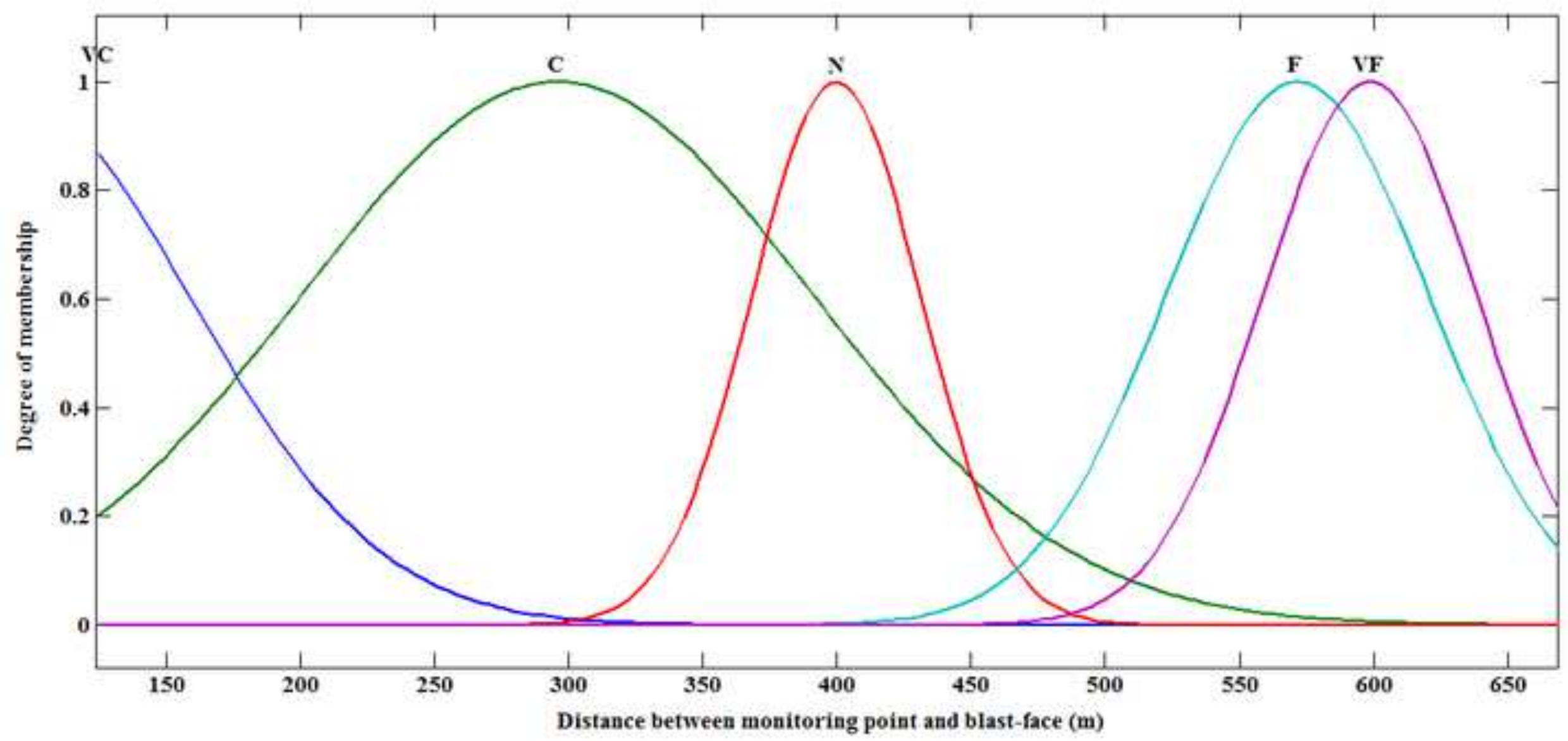




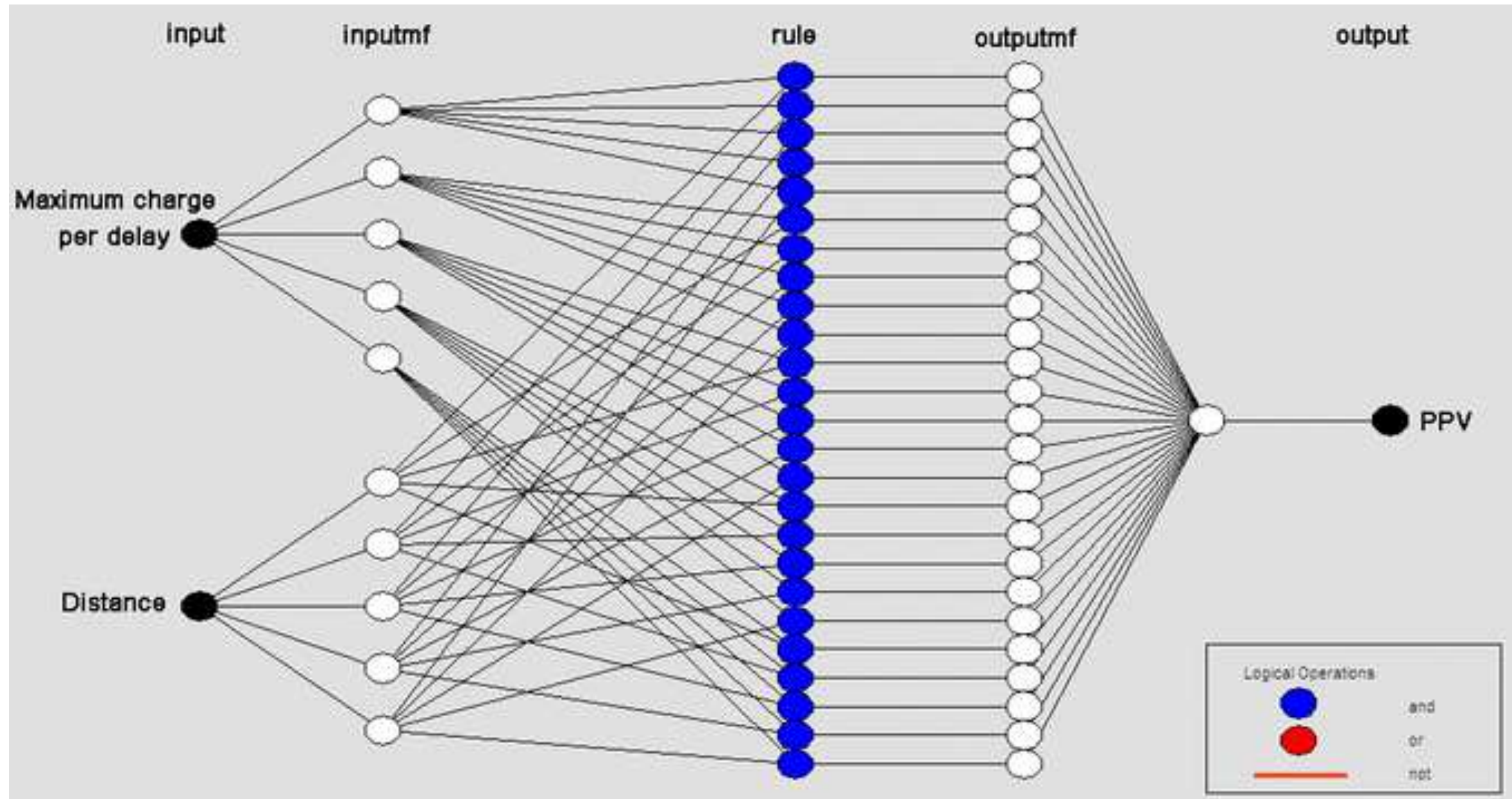




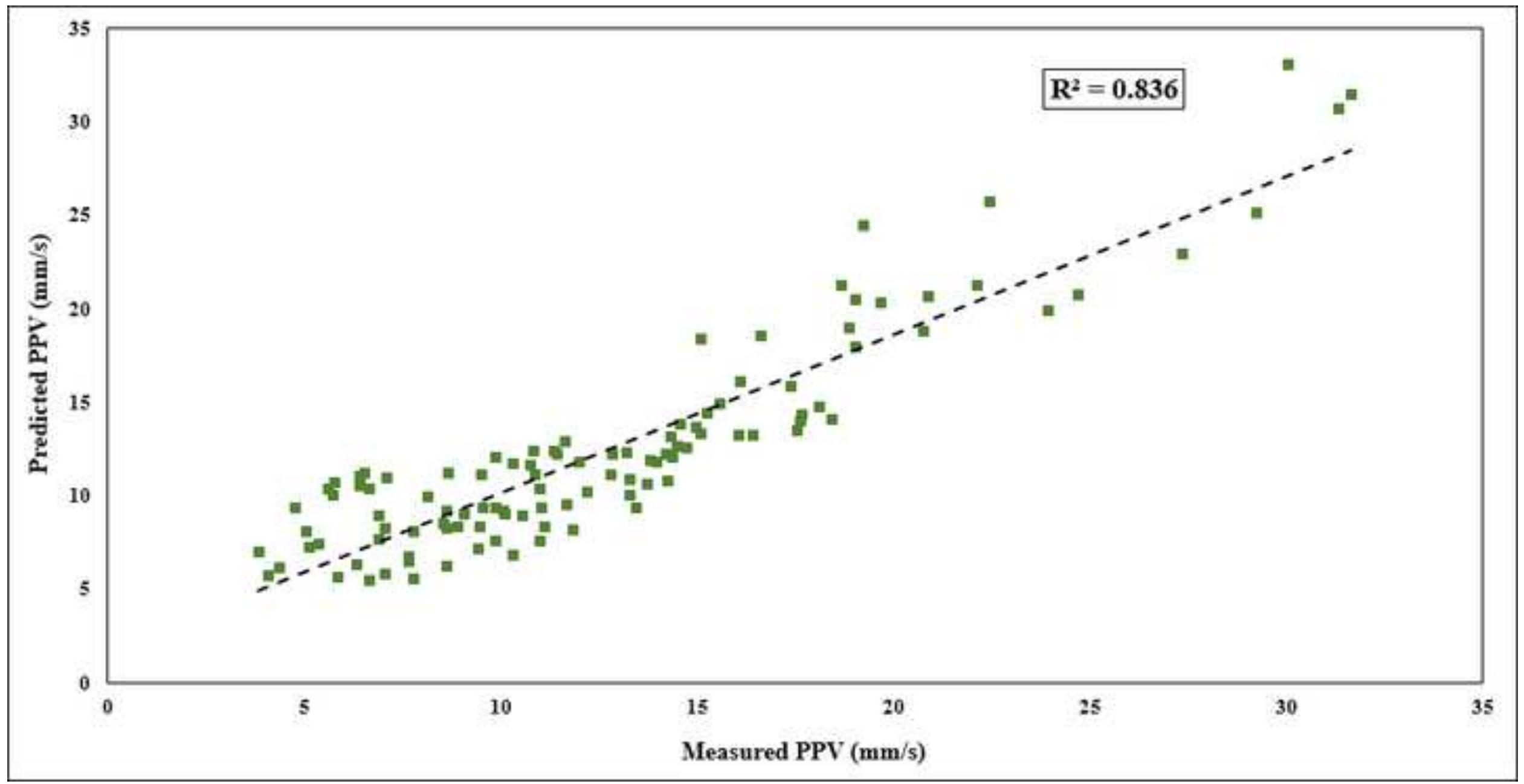



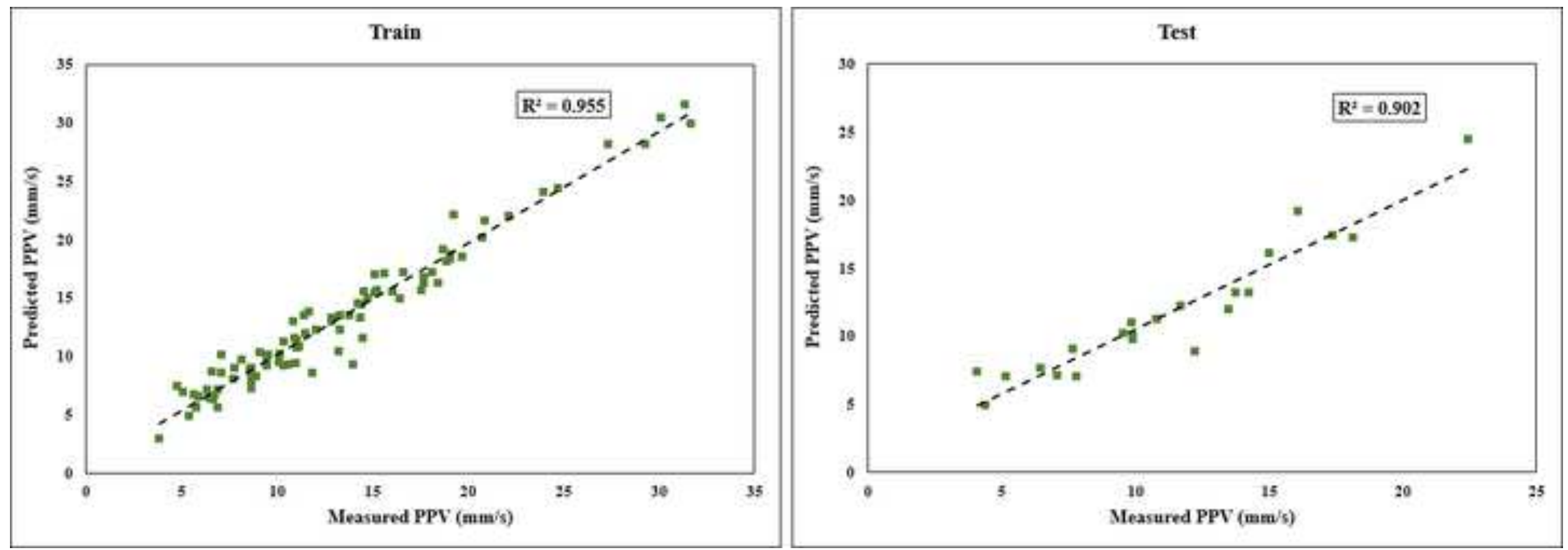

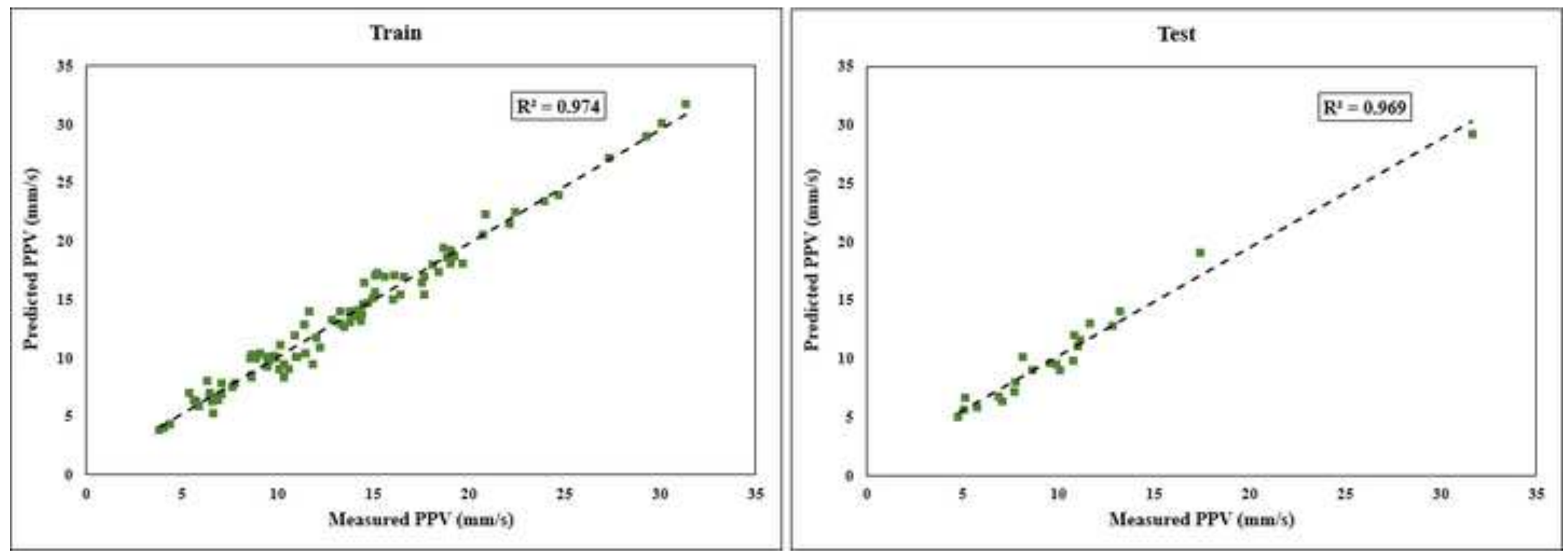


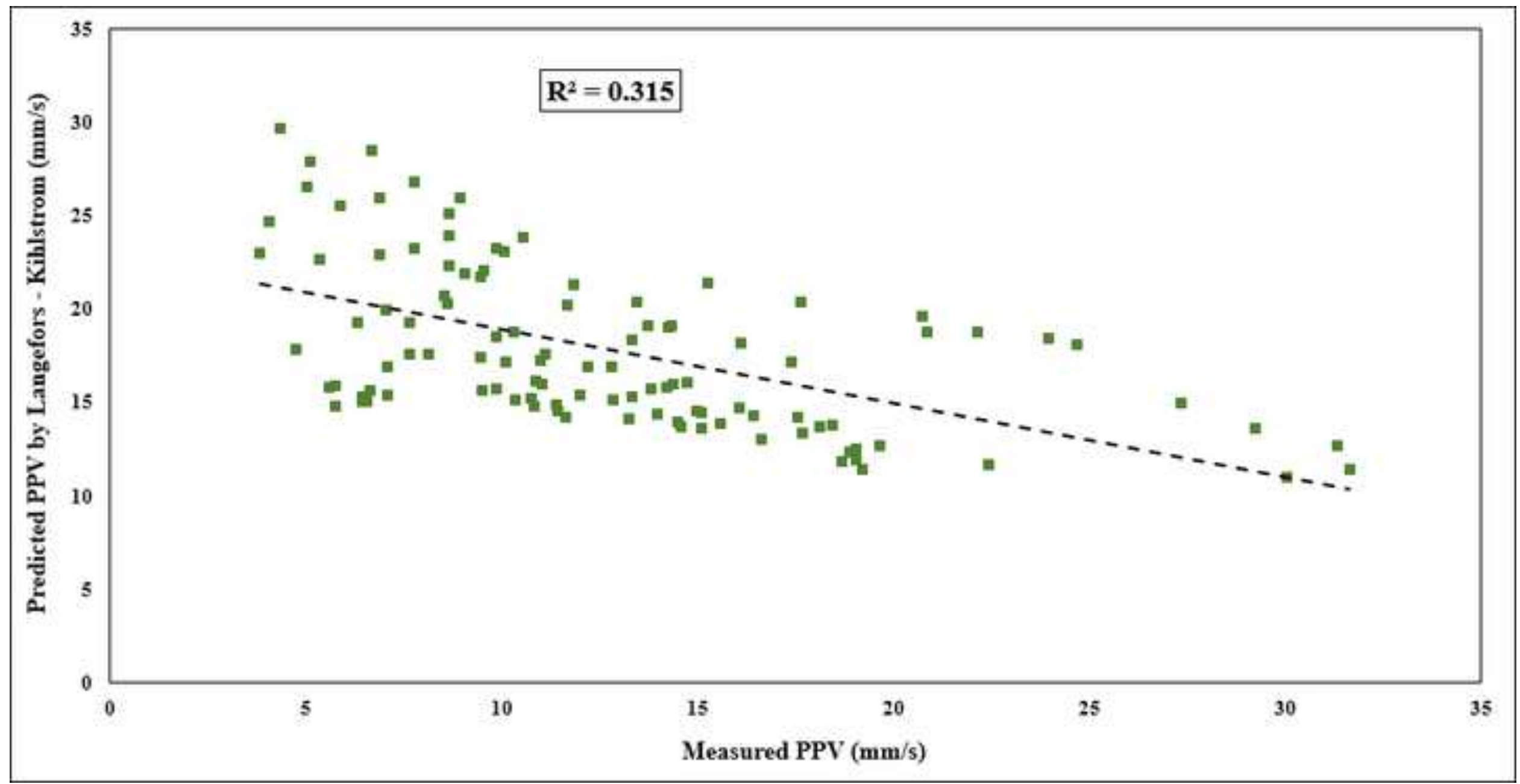




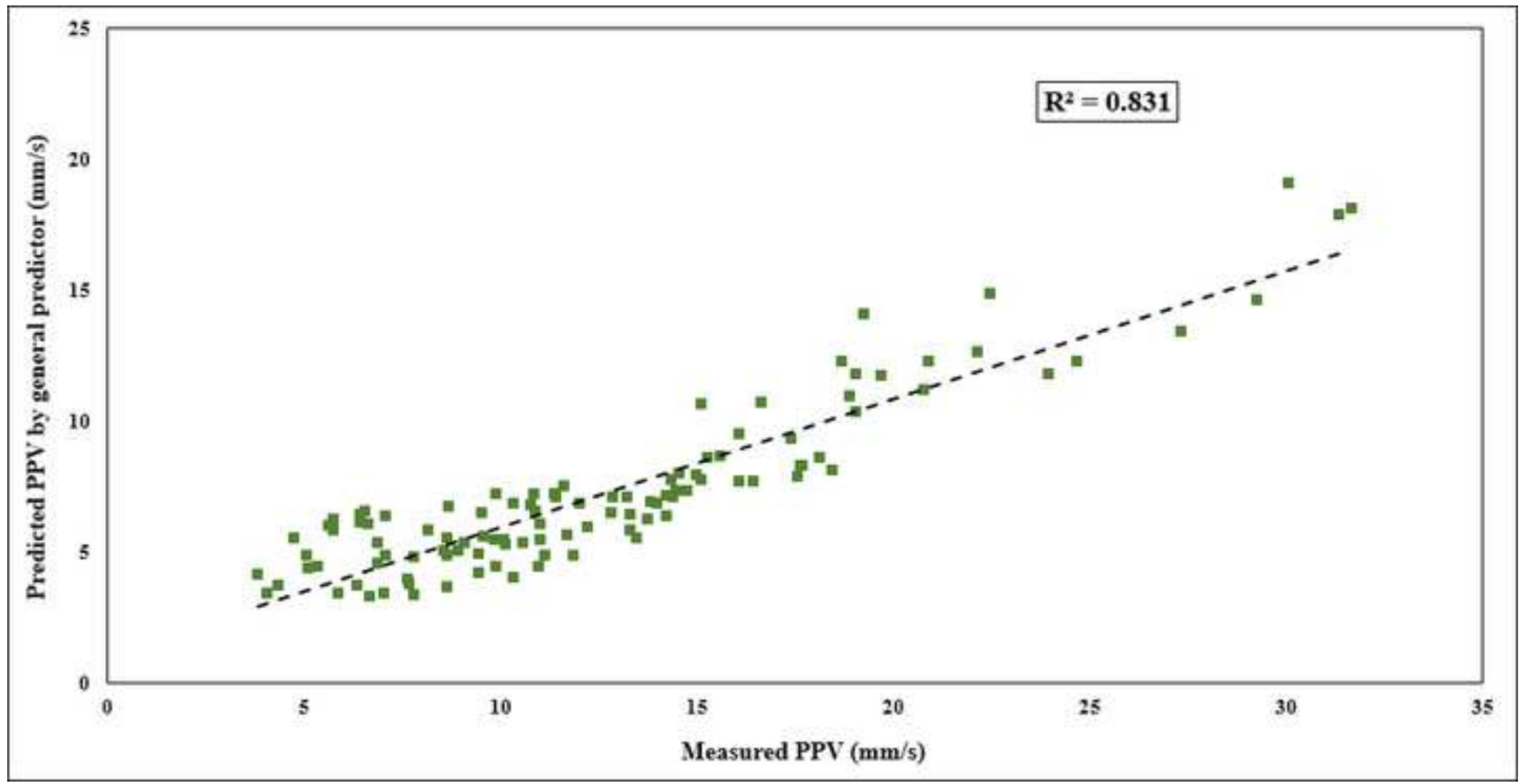




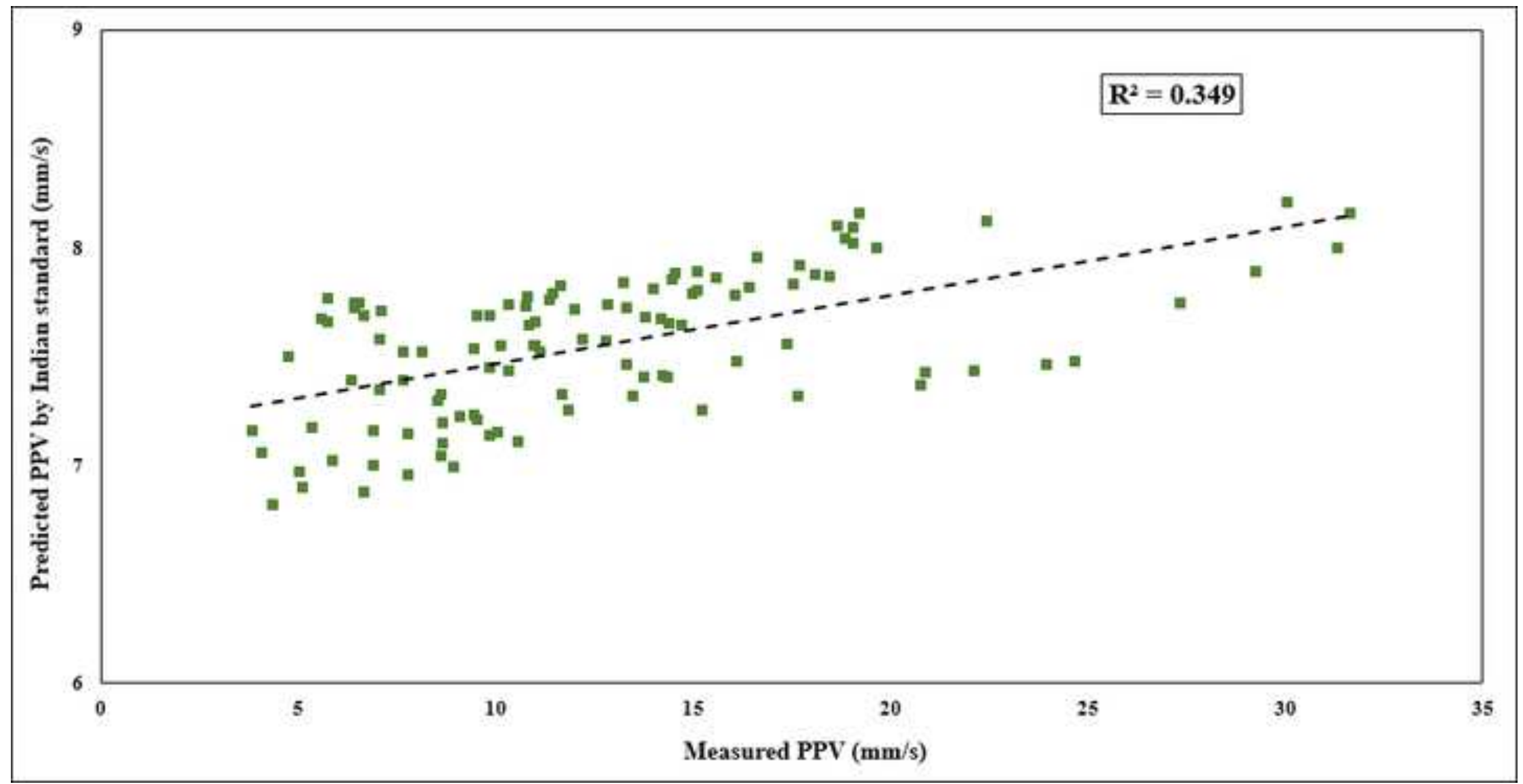




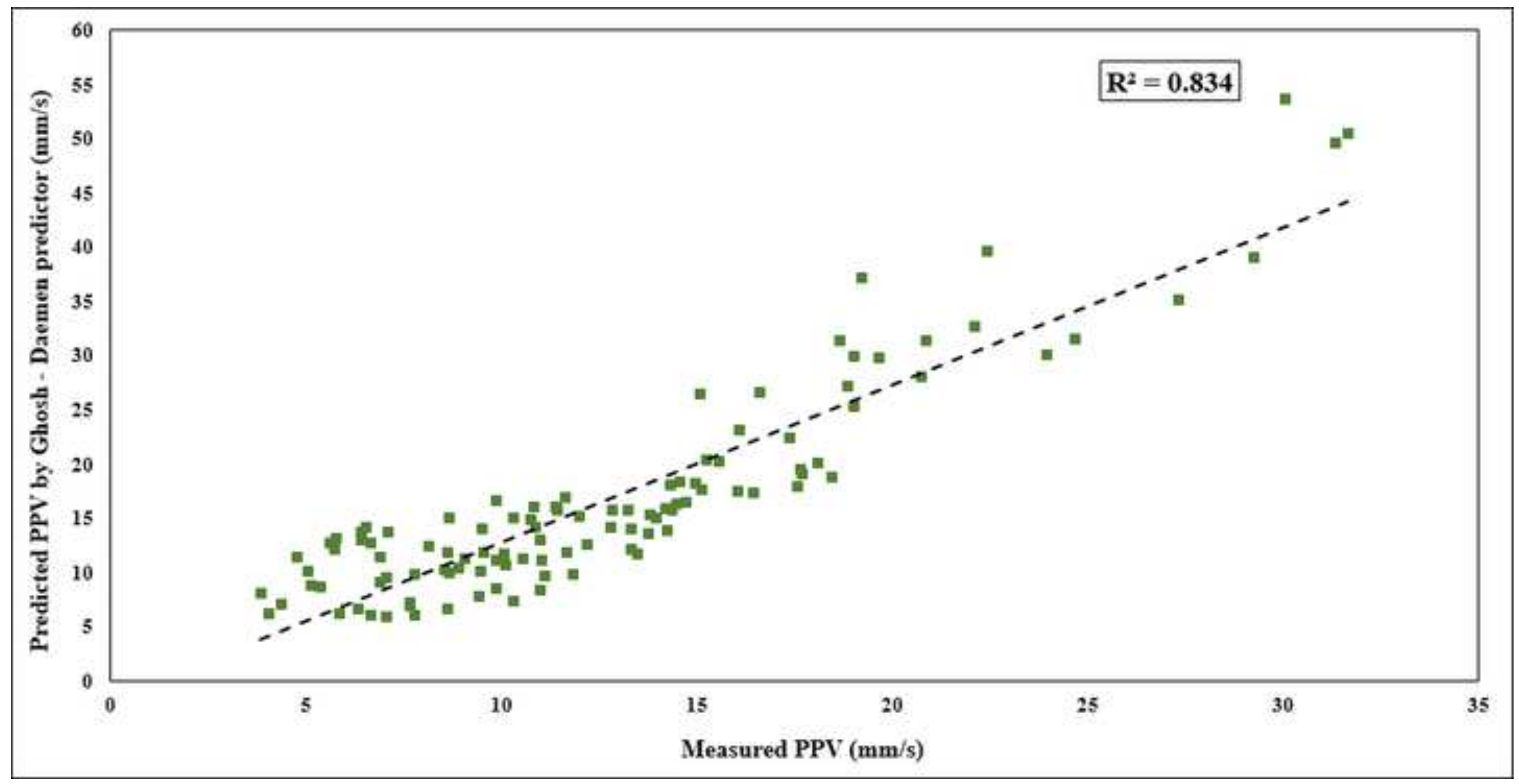




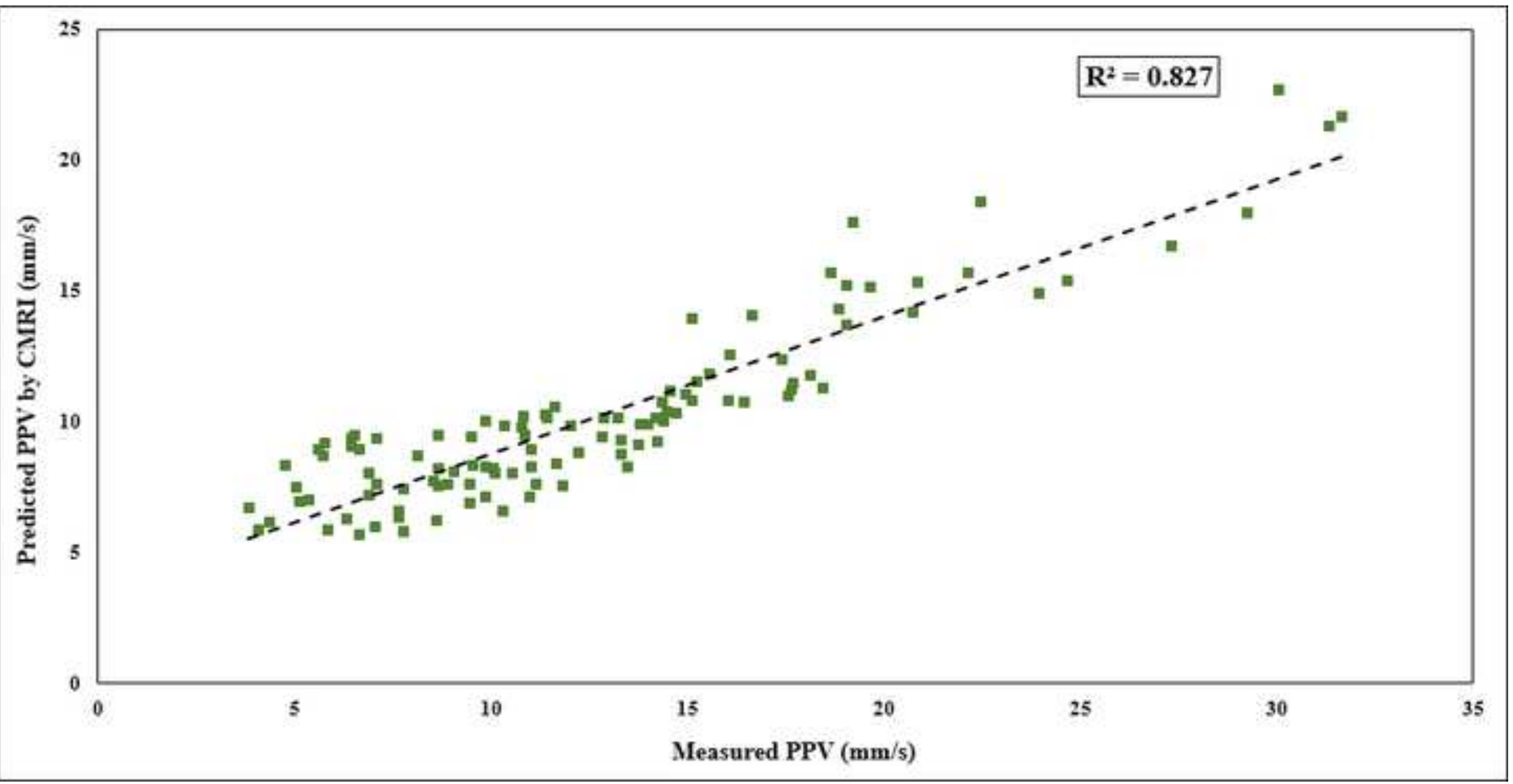


Table 1 Recent works on PPV prediction using soft computation techniques

\begin{tabular}{|c|c|c|c|c|}
\hline Reference & Technique & Input & No. of dataset & $\mathbf{R}^{2}$ \\
\hline Khandelwal and Singh (2009) & ANN & $\mathrm{BI}, \mathrm{S}, \mathrm{B}, \mathrm{HD}, \mathrm{D}, \mathrm{VOD}, \mathrm{Vp}, \mathrm{E}, \mathrm{v}, \mathrm{C}$ & 154 & $\mathrm{R}^{2}=0.98$ \\
\hline Monjezi et al. (2010) & ANN & BS, N, D, UCS, C, DPR & 269 & $\mathrm{R}^{2}=0.95$ \\
\hline Monjezi et al. (2011) & ANN & HD, ST, D, C & 182 & $\mathrm{R}^{2}=0.95$ \\
\hline Khandelwal et al. (2011) & ANN & $\mathrm{D}, \mathrm{C}$ & 130 & $\mathrm{R}^{2}=0.92$ \\
\hline Mohamed (2011) & ANN, FIS & $\mathrm{D}, \mathrm{C}$ & 162 & $\begin{array}{l}\mathrm{R}_{\mathrm{ANN}}^{2}=0.94 \\
\mathrm{R}_{\mathrm{FIS}}^{2}=0.90\end{array}$ \\
\hline Fisne et al. (2011) & FIS & $\mathrm{D}, \mathrm{C}$ & 33 & $\mathrm{R}^{2}=0.92$ \\
\hline Li et al. (2012) & SVM & $\mathrm{D}, \mathrm{C}$ & 32 & $\mathrm{R}^{2}=0.89$ \\
\hline Mohamadnejad et al. (2012) & SVM, ANN & $\mathrm{D}, \mathrm{C}$ & 37 & $\begin{array}{l}\mathrm{R}_{\text {SVM }}^{2}=0.89 \\
\mathrm{R}^{2}{ }_{\mathrm{ANN}}=0.85\end{array}$ \\
\hline Ghasemi et al. (2013) & FIS & B, S, ST, N, C, D & 120 & $\mathrm{R}^{2}=0.95$ \\
\hline Monjezi et al. (2013) & ANN & C, D. TC & 20 & $\mathrm{R}^{2}=0.93$ \\
\hline Jahed Armaghani et al. (2013) & ANN-PSO & HD, S, B, ST, PF, C, DI, N, RD, SD & 44 & $\mathrm{R}^{2}=0.94$ \\
\hline Hajihassani et al. (2014b) & ANN-ICA & $\mathrm{BS}, \mathrm{ST}, \mathrm{D}, \mathrm{C}, \mathrm{Vp}, \mathrm{E}$ & 95 & $\mathrm{R}^{2}=0.98$ \\
\hline Ghoraba et al. (2015) & ANN & BS, D, C, ST, HD & 115 & $\mathrm{R}^{2}=0.98$ \\
\hline
\end{tabular}


Table 2 Parameters used in the predictive model with their categories

\begin{tabular}{lcccccc}
\hline Parameter & Category & Unit & Symbol & Minimum & Maximum & Average \\
\hline Maximum charge per delay & Input & $(\mathrm{Kg})$ & MC & 106 & 374 & 255.47 \\
Distance* & Input & $(\mathrm{m})$ & $\mathrm{D}$ & 125 & 670 & 346.37 \\
Peak particle velocity & Output & $(\mathrm{mm} / \mathrm{s})$ & PPV & 3.83 & 31.65 & 12.72 \\
\hline \multicolumn{1}{c}{ * Distance between monitoring point and blast-face } & & & & &
\end{tabular}

* Distance between monitoring point and blast-face 
Table 3 Recommended number of nodes for hidden layers (Sonmez et al. 2006)

\begin{tabular}{ll}
\hline Heuristic & Reference \\
\hline$\leq 2 \times N_{i}+1$ & Hecht-Nielsen (1987) \\
$3 N_{i}$ & Hush (1989) \\
$\left(N_{i}+N_{0}\right) / 2$ & Ripley (1993) \\
$2+N_{0} \times N_{i}+0.5 N_{0} \times\left(N_{0}^{2}+N_{i}\right)-3$ & \\
\hline$N_{i}+N_{0}$ & Paola (1994) \\
$\sqrt{N_{i} \times N_{0}}$ & Wang (1994) \\
$2 N_{i}$ & Masters (1994) \\
\hline$N_{\mathrm{i}}:$ number of input neuron, $\mathrm{N}_{0}$ : number of output neuron. & Kaastra and Boyd (1996)
\end{tabular}


Table 4 Performances of trained ANN models to predict PPV

\begin{tabular}{|c|c|c|c|c|c|c|c|c|c|c|c|}
\hline \multirow{4}{*}{$\begin{array}{l}\text { Model } \\
\text { No. }\end{array}$} & \multirow{4}{*}{$\begin{array}{c}\text { Nodes in } \\
\text { hidden layers }\end{array}$} & \multicolumn{10}{|c|}{ Network Result } \\
\hline & & \multirow{2}{*}{\multicolumn{2}{|c|}{$\begin{array}{c}\text { Iteration } 1 \\
\text { RMSE }\end{array}$}} & \multirow{2}{*}{\multicolumn{2}{|c|}{$\begin{array}{c}\text { Iteration } 2 \\
\text { RMSE } \\
\end{array}$}} & \multirow{2}{*}{\multicolumn{2}{|c|}{$\begin{array}{c}\text { Iteration } 3 \\
\text { RMSE }\end{array}$}} & \multirow{2}{*}{\multicolumn{2}{|c|}{$\begin{array}{c}\text { Iteration } 4 \\
\text { RMSE }\end{array}$}} & \multirow{2}{*}{\multicolumn{2}{|c|}{$\begin{array}{c}\text { Iteration } 5 \\
\text { RMSE }\end{array}$}} \\
\hline & & & & & & & & & & & \\
\hline & & Train & Test & Train & Test & Train & Test & Train & Test & Train & Test \\
\hline 1 & 1 & 2.709 & 2.778 & 2.755 & 2.387 & 2.608 & 3.013 & 2.655 & 2.839 & 2.714 & 2.587 \\
\hline 2 & 2 & 2.585 & 2.583 & 2.689 & 2.705 & 2.071 & 2.781 & 2.206 & 2.759 & 2.329 & 2.182 \\
\hline 3 & 3 & 1.865 & 2.507 & 2.112 & 2.539 & 2.091 & 2.438 & 1.976 & 2.665 & 2.059 & 2.410 \\
\hline 4 & 4 & 1.949 & 2.220 & 2.021 & 2.118 & 2.163 & 2.471 & 2.055 & 2.393 & 1.825 & 2.491 \\
\hline 5 & 5 & 1.425 & 1.777 & 1.684 & 2.285 & 1.662 & 2.250 & 1.377 & 2.173 & 1.418 & 1.673 \\
\hline 6 & 6 & 1.261 & 1.726 & 1.327 & 1.538 & 1.576 & 1.653 & 1.597 & 1.654 & 1.698 & 2.473 \\
\hline
\end{tabular}


Table 5 Performances of the 5 ANFIS models in predicting PPV

\begin{tabular}{ccc}
\hline \multirow{2}{*}{ ANFIS Model } & \multicolumn{2}{c}{ RMSE } \\
\cline { 2 - 3 } & Train & Test \\
\hline 1 & 1.114 & 1.642 \\
2 & 1.217 & 1.599 \\
3 & 1.020 & 1.252 \\
4 & 0.983 & 1.017 \\
5 & 1.303 & 1.595 \\
\hline
\end{tabular}


Table 6 Empirical PPV models

\begin{tabular}{lll}
\hline Reference & Equation & Site Constant for Granite \\
\hline Langefors - Kihlstrom (1963) & $P P V=K\left[\sqrt{\left.\left(M C / D^{2 / 3}\right)\right]^{B}}\right.$ & K: 44.43, B: -1.18 \\
General predictor by Davies et al. (1964) & $P P V=K D^{-B}(M C)^{A}$ & K: 212.27, B: 1.09, A: 0.52 \\
Bureau of Indian Standard (1973) & $P P V=K\left[\left(M C / D^{2 / 3}\right)\right]^{B}$ & K: 6.33, B: 0.22 \\
Ghosh - Daemen predictor (1983) & $P P V=K[D / \sqrt{M C}]^{-B} e^{-\alpha D}$ & K: $780.36, \mathrm{~B}: 1.26, \alpha: 0.0004$ \\
CMRI by Roy (1993) & $P P V=n+K[D / \sqrt{M C}]^{-1}$ & K: $168.91, \mathrm{n}: 1.57$
\end{tabular}

$P P \bar{V}$ : Peak particle velocity (mm/s), MC: Maximum charge per delay (kg), D: Distance between blast face and vibration monitoring point (m), K, B, A, $\alpha, \mathrm{n}$ : Site constants. 
Table 7 Performance indices of all utilized models for prediction of PPV

\begin{tabular}{lccc}
\hline \multirow{2}{*}{ Predictive Model } & \multicolumn{3}{c}{ Performance Indices } \\
\cline { 2 - 4 } & $\mathbf{R}^{\mathbf{2}}$ & RMSE & VAF (\%) \\
\hline Langefors - Kihlstrom & 0.315 & 10.473 & -128.274 \\
General predictor & 0.831 & 6.391 & 69.293 \\
Indian Standard & 0.349 & 7.821 & 6.024 \\
Ghosh - Daemen predictor & 0.834 & 6.233 & 37.996 \\
CMRI & 0.827 & 4.078 & 72.068 \\
Proposed model based on USBM & 0.836 & 2.469 & 83.629 \\
ANN & 0.949 & 1.372 & 94.895 \\
ANFIS & 0.973 & 0.987 & 97.345 \\
\hline
\end{tabular}

